\title{
Interconnected Parallel Circuits between Rat Nucleus Accumbens and Thalamus Revealed by Retrograde Transynaptic Transport of Pseudorabies Virus
}

\author{
Patricio O’Donnell, ${ }^{1}$ Antonieta Lavín, ${ }^{1}$ Lynn W. Enquist, ${ }^{2}$ Anthony A. Grace, ${ }^{1}$ and J. Patrick Card ${ }^{1}$ \\ ${ }^{1}$ Departments of Neuroscience and Psychiatry, Center for Neuroscience, University of Pittsburgh, Pittsburgh, \\ Pennsylvania 15260, and 2Department of Molecular Biology, Princeton University, Princeton, New Jersey 08544
}

One of the primary outputs of the nucleus accumbens is directed to the mediodorsal thalamic nucleus (MD) via its projections to the ventral pallidum (VP), with the core and shell regions of the accumbens projecting to the lateral and medial aspects of the VP, respectively. In this study, the multisynaptic organization of nucleus accumbens projections was assessed using intracerebral injections of an attenuated strain of pseudorabies virus, a neurotropic $\alpha$ herpesvirus that replicates in synaptically linked neurons. Injection of pseudorabies virus into different regions of the MD or reticular thalamic nucleus (RTN) produced retrograde transynaptic infections that revealed multisynaptic interactions between these areas and the basal forebrain. Immunohistochemical localization of viral antigen at short postinoculation intervals confirmed that the medial MD (m-MD) receives direct projections from the medial VP, rostral RTN, and other regions previously shown to project to this region of the thalamus. At longer survival intervals, injections confined to the $\mathrm{m}-\mathrm{MD}$ resulted in transynaptic infection of neurons in the accumbens shell but not in the core. Injections that also included the central segment of the MD produced retrograde infection of neurons in the lateral VP and the polymorph (pallidal) region of the olfactory tubercle (OT) and transynaptic infection of a small number of neurons in the rostral accumbens core. Injections in the lateral MD resulted in retrograde infection in the globus pallidus (GP) and in transynaptic infection in the caudateputamen. Viral injections into the rostroventral pole of the RTN infected neurons in the medial and lateral VP and at longer postinoculation intervals, led to transynaptic infection of scattered neurons in the shell and core. Injection of virus into the intermediate RTN resulted in infection of medial VP neurons and second-order infection of neurons in the accumbens shell. Injections in the caudal RTN or the lateral MD resulted in direct retrograde labeling of cells within the GP and transynaptic infection of neurons in the caudate-putamen. These results indicate that the main output of VP neurons receiving inputs from the shell of the accumbens is heavily directed to the $\mathrm{m}-\mathrm{MD}$, whereas a small number of core neurons appear to influence the central MD via the lateral VP. Further segregation in the flow of information to the MD is apparent in the organization of VP and GP projections to subdivisions of the RTN that give rise to $\mathrm{MD}$ afferents. Collectively, these data provide a morphological basis for the control of the thalamocortical system by ventral striatal regions, in which parallel connections to the RTN may exert control over activity states of cortical regions.

Key words: transneuronal tracing; reticular thalamic nucleus; ventral pallidum; nucleus accumbens; mediodorsal thalamic nucleus; prefrontal cortex; globus pallidus; pseudorabies virus
The nucleus accumbens, which is the ventral extension of the striatum, has been implicated in a number of psychiatric diseases such as schizophrenia (Snyder, 1973; Matthysse, 1981; Csernansky et al., 1991; Gray et al., 1991; Grace, 1992) and Tourette's syndrome (Comings, 1987; Braun et al., 1993). This structure is believed to subsume an integrative role in higher cortical functions, given its position as an interface between limbic and motor systems (Mogenson et al., 1980). The multisynaptic circuitry linking the striatum [i.e., the nucleus accumbens and caudate-putamen $(\mathrm{CPu})]$ and basal forebrain with cortical areas is organized in the form of several parallel loops (Alexander and Crutcher, 1990;

Received July 19, 1996; revised Dec. 3, 1996; accepted Dec. 31, 1996.

This work was supported by National Institutes of Health Grants MH53574 (J.P.C.), NINDS33506 (L.W.E.), and MH45156 and MH01055 (A.A.G.); and a National Alliance for Research on Schizophrenia and Depression Young Investigator Award (P.O.). We thank Ms. Jen-Shew Yen for her excellent technical assistance and Dr. Susan R. Sesack and Dr. Holly Moore for comments on this manuscript. We also thank Dr. Robert Y. Moore for generously providing the use of his BSL-2 facility.

Correspondence should be addressed to Dr. Patricio O'Donnell, Department of Neuroscience, 446 Crawford Hall, University of Pittsburgh, Pittsburgh, PA 15260.

Copyright (C) 1997 Society for Neuroscience 0270-6474/97/172143-25\$05.00/0
Berendse and Groenewegen, 1990; Groenewegen et al., 1990). The nucleus accumbens receives glutamatergic projections from the prefrontal cortex (PFC) (Beckstead, 1979; Fuller et al., 1987), hippocampus (DeFrance and Yoshihara, 1975; Kelley and Domesick, 1982; DeFrance et al., 1985), and amygdala (Swanson and Cowan, 1975; Groenewegen et al., 1980; McDonald, 1991) that converge on single accumbens neurons (O'Donnell and Grace, 1995b). In turn, the accumbens sends its primary output to the ventral pallidum (VP) (Heimer and Wilson, 1975; Mogenson et al., 1983), which inhibits thalamocortical activity by way of its projections to the mediodorsal thalamic nucleus (MD) (Young et al., 1984; Haber et al., 1985; Lavín and Grace, 1994).

Two major subdivisions of the nucleus accumbens have been defined according to distinct anatomical connections (Heimer et al., 1991; Brog et al., 1993; Zahm and Heimer, 1993). The portion of the nucleus accumbens surrounding the anterior commissure, known as the core, has been reported to receive its primary cortical input from the prelimbic (PL) PFC (Sesack et al., 1989; Berendse et al., 1992; Brog et al., 1993; Montaron et al., 1996) and dorsal subiculum (Groenewegen et al., 1991; Brog et al., 1993) and projects to the dorsolateral aspect of the VP (Zahm and 
Heimer, 1990; Heimer et al., 1991). On the other hand, the medial-ventral aspect of the accumbens, called the shell, receives input primarily from the infralimbic (IL) PFC (Berendse et al., 1992; Brog et al., 1993) and the ventral subiculum (Kelley and Domesick, 1982; Yang and Mogenson, 1984; Sesack and Pickel, 1990; Aylward and Totterdell, 1993; Brog et al., 1993) and sends projections to the ventromedial part of the VP (Zahm and Heimer, 1990; Heimer et al., 1991). In addition to differences in their connectivity, the core and shell regions of the nucleus accumbens differ in neurochemical markers (Záborszky et al., 1985; Meredith et al., 1989, 1996; Deutch and Cameron, 1992; Jongen-Rêlo et al., 1994a,b), cell morphology (Meredith et al., 1992, 1993; O’Donnell and Grace, 1993b), physiological properties (Pennartz et al., 1992; O'Donnell and Grace, 1993a,b; Onn and Grace, 1995), and responses to pharmacological and behavioral manipulations (Deutch et al., 1992; Kalivas and Duffy, 1995; O'Donnell and Grace, 1995a).

The present study was designed to determine whether the pathways originating in the core and shell regions of the accumbens remain segregated within the VP and in the efferent projections of this area to the thalamocortical system. Although the primary thalamic target of the VP is the MD (Young et al., 1984; Haber et al., 1985; Heimer et al., 1991; Groenewegen et al., 1993), a projection from the VP to the reticular thalamic nucleus (RTN) has also been reported in the rat (Cornwall et al., 1990; Groenewegen et al., 1993). Furthermore, electrical stimulation of the lateral VP induces occasional monosynaptic responses in the rat RTN (Lavín and Grace, 1994), suggesting that a subset of VP neurons may project to the RTN. Nonetheless, the multisynaptic organization of the accumbens-VP-thalamic connectivity has been difficult to establish with conventional tract tracing or electrophysiological approaches, because these methods only define one order of synaptic contact. Therefore, resolution of the organization of connections between the nucleus accumbens and thalamus requires a tracer that will cross synapses and label second-order synaptically linked neurons. This was achieved by using a neurotropic swine $\alpha$ herpesvirus (pseudorabies virus, PRV) that has proven to be an effective tracer of multisynaptic pathways in a variety of systems (for review, see Card and Enquist, 1994; Loewy, 1995; Ugolini, 1995; Enquist and Card, 1996). The experimental approach used in this study is based on the demonstrated ability of this family of neurotropic viruses to replicate within synaptically linked populations of neurons after intracerebral injection (Zemanick et al., 1991; Middleton and Strick, 1994). Our data demonstrate a segregation of multisynaptic projections through the VP that arise in either the core or shell of the accumbens and terminate in either the MD or reticular thalamic nuclei.

Parts of these data were presented at the 1995 Society for Neuroscience meeting (O'Donnell et al., 1995).

\section{MATERIALS AND METHODS}

Animal handling and preparation. Adult male Sprague Dawley rats (200$420 \mathrm{gm}$ at time of virus injection) were used in these experiments. They were housed in pairs with food and water available ad libitum, and under a 12:12 hr light/dark cycle (light on at 6:00 A.M.). Animal handling and experimental protocols were in accordance with the NIH Guide for the Care and Use of Laboratory Animals and were approved by the University of Pittsburgh Animal Care and Use Committee. Injections of PRV were administered to anesthetized animals in a Biosafety Level 2 containment facility in accordance with regulations stipulated in Health and Human Services Publication No. 88-8395 entitled "Biosafety in Microbiological and Biomedical Laboratories". Animals were inoculated, housed, and killed in this facility.

Virus. An attenuated strain of PRV (Bartha strain) was used in this study. The virus, initially developed as a swine vaccine in 1961 (Bartha, 1961), exhibits reduced virulence compared with wild-type strains and replicates efficiently in rodent CNS (Enquist, 1994; Card and Enquist, 1995). It has been used extensively for characterizing multisynaptic circuits associated with the visual system (Card et al., 1991, 1992; Moore et al., 1995) and autonomic nervous system (Strack et al., 1989; Card et al., 1990, 1993; Strack and Loewy, 1990; Jansen et al., 1992, 1995; Nadelhaft et al., 1992; Standish et al., 1995; Vizzard et al., 1995). More recently, intracerebral injection of this strain of virus has been shown to produce retrograde transneuronal patterns of infection (Enquist et al., 1993; Leak et al., 1995). The virus used in the present study was grown in PK 15 cells to a titer of $1.4 \times 10^{9}$ plaque forming units $(\mathrm{pfu})$ per milliliter. Procedures for growing and harvesting the virus have been published elsewhere (Enquist and Card, 1996). Aliquots of virus were stored at $-80^{\circ} \mathrm{C}$ before use and thawed immediately before injection. Unused portions of each aliquot were inactivated with Chlorox and discarded.

Antibodies. A rabbit polyclonal antiserum (Rb134) generated against acetone-inactivated virus was used to localize infected neurons. The serum recognizes numerous virion proteins and produces robust immunohistochemical staining of the somata and dendrites of PRV-infected neurons (Card and Enquist, 1994). Rb134 was used at a dilution of $1: 10,000$. In some cases, PRV was co-injected with the $\beta$ fragment of cholera toxin (CT), a conventional tracer that identifies one order of synaptic contact. A goat polyclonal antiserum (List Biochemicals, Campbell, CA) was used at a 1:20,000 dilution to localize CT in tissue from these animals.

Calbindin immunolocalization provided a precise definition of the boundaries of the core and shell regions of the nucleus accumbens. This calcium-binding protein is densely concentrated in the accumbens core and absent in the shell (Zahm and Heimer, 1993), and it has been shown to be the most accurate marker for core-shell boundaries (Jongen-Rêlo et al., 1994b). Calbindin was localized using a rabbit polyclonal antiserum at a final dilution of 1:20,000. The extent of the electrolytic lesion in two animals lesioned in the VP and globus pallidus (GP) (see following section) was assessed by means of immunohistochemical localization of glial fibrillar acidic protein, an intermediate filament protein found within astrocytes, with a mouse monoclonal antibody (Chemicon, Temecula, CA) used at a dilution of 1:10,000.

Injection procedures. Animals were anesthetized with ketamine and xylazine $(60 \mathrm{mg} / \mathrm{kg}$ ketamine, $7 \mathrm{mg} / \mathrm{kg}$ xylazine, i.p.) before being placed in a stereotaxic apparatus (Kopf, Tujunga, CA). Virus was injected through a $1 \mu$ l Hamilton syringe lowered into target areas through a hole drilled in the skull. The stereotaxic coordinates used, obtained from a rat brain stereotaxic atlas (Paxinos and Watson, 1986), were as follows. For the medial segment of the MD (m-MD; 10 rats) coordinates were anteroposterior (AP): -3.2 , mediolateral (ML): 0.5, dorsoventral (DV): -5.9; for the central segment of the MD (c-MD; 5 rats), AP: -3.2 , ML: 0.7 , DV: -5.8 ; and for the lateral segment of the MD (1-MD; 6 rats), AP: -3.3, ML: 1.0, DV: -5.7 . Injections in the RTN were grouped in the following three rostrocaudal locations. The rostral pole of the RTN (AP: -1.3 to -1.5 , ML: 1.6 , DV: $-6.3 ; 2$ rats); the intermediate RTN (AP: -1.5 to -2.0 , ML: $2.0, \mathrm{DV}:-6 ; 2$ rats); and the caudal RTN (AP: -2.0 to -3.3 , ML: 3.8 , DV: $-5.6 ; 4$ rats). A total of $100-200 \mathrm{nl}$ of the PRV-Bartha $\left(1-2 \times 10^{5} \mathrm{pfu}\right)$ was injected at a rate of $10 \mathrm{nl} / \mathrm{min}$, and the syringe was left in place for an additional $5 \mathrm{~min}$ to reduce reflux of the viral inoculum up the cannula tract. A subset of animals were injected with a mixture of PRV and the $\beta$ subunit of CT. The CT was diluted to $0.25 \%$ with isotonic saline, whereupon $10 \mu \mathrm{l}$ was mixed with $10 \mu \mathrm{l}$ of PRV and $200 \mathrm{nl}\left(2 \times 10^{5} \mathrm{pfu}\right)$ of the mixture was injected intracerebrally at 10 $\mathrm{nl} / \mathrm{min}$. The concentration of virus injected in all experiments produces an infection in $100 \%$ of animals after intravitreal inoculation (Card et al., 1995).

Two animals received an electrolytic lesion in the VP or the GP before receiving the PRV injection into the MD. The lesions were performed under deep anesthesia using a coated insect pin and a current generator (Grass, Quincy, MA). Monopolar current (4 mA for $20 \mathrm{sec}$ ) was passed though the electrode, placed in the rostral VP region (AP: 0.2, ML: 0.8, DV: -8.3). After recovery, the animals were returned to their home cage. One week later, PRV was injected into the m-MD, and the animals were killed for immunohistochemical detection of viral infection in the neuraxis at 60 and $62 \mathrm{hr}$ postinoculation.

Tissue processing. After postinoculation periods ranging from 36 to 72 $\mathrm{hr}$, the animals were deeply anesthetized with an overdose of ketamine and xylazine and perfused transcardially with a buffered aldehyde fixative (McLean and Nakane, 1974). The brains were removed, post-fixed for 1 
hr at $4^{\circ} \mathrm{C}$, and cryoprotected in $20 \%$ sucrose in $0.1 \mathrm{M}$ phosphate buffer for a minimum of $12 \mathrm{hr}$ before they were cut using a freezing microtome. The entire brain was sectioned serially in the coronal plane at $35 \mu \mathrm{m}$ per section and collected sequentially in six bins of buffer. One bin of tissue was processed immediately for immunohistochemical localization of viral antigen using the avidin-biotin modification of the immunoperoxidase procedures (Hsu et al., 1981) and Vectastain Elite reagents (Vector Laboratories, Burlingame. CA). The details of this procedure, as it is applied in our laboratory, have been published (Card and Enquist, 1994). The remaining bins of tissue were transferred to a cryopreservant (Watson et al., 1986) and stored at $-20^{\circ} \mathrm{C}$ to preserve antigenicity. Some of this tissue was subsequently processed with Rb134 to provide more frequent series of sections for analysis of viral transport. Other bins of tissue were processed for localization of CT immunoreactivity to define first-order connections or for immunohistochemical localization of calbindin to define core-shell boundaries.

\section{RESULTS}

PRV was injected intracerebrally in 52 rats. Twenty-nine of these animals contained injection sites that included one or more of the subdivisions of the MD or the RTN. Twelve animals contained injections that missed the MD or RTN. These cases were used as controls for the specificity of the results obtained from injection of virus into either the MD or the RTN. In two cases, electrolytic lesions of the VP or GP preceded injection of virus into the $\mathrm{m}-\mathrm{MD}$. Eleven cases were discarded because of poor placement of the injection $(n=7)$ or failure to detect viral immunoreactivity at short postinoculation intervals ( $n=4 ; 36-44 \mathrm{hr}$ survival). Temporal analysis of the extent of viral replication and transport indicated that postinoculation survival intervals of 36-50 hr were the most effective time span for characterizing the multisynaptic connections between the MD, RTN, and nucleus accumbens. At longer survival intervals, the more extensive transynaptic passage of virus made it more difficult to ascertain the routes of viral transport.

\section{Diffusion of PRV from the injection site}

Controlled injection of PRV resulted in very little diffusion of virus from the site of injection, as demonstrated by the restricted distribution of infected cells at injection sites, even at the longest postinoculation intervals (Fig. $1 A, C, E$; see also Figs. $3 A, 5 A, 6 A$, $7 A$ ). Analysis of viral immunoreactivity at the injection sites in closely spaced sections revealed that infected neurons were confined to the immediate vicinity of the injection cannula. The effective area of viral injection, as defined by the distribution of neurons displaying viral immunoreactivity, ranged between 100 and $500 \mu \mathrm{m}$ in diameter surrounding the tip of the cannula. Injection of equivalent volumes of PRV produced smaller injection sites in the m-MD compared with the 1-MD (compare Figs. $3 A$ and $5 A$ ), and the injections in any region of the RTN produced the largest injection sites (see Figs. $6 A, 7 A$ ). Co-injection of the $\beta$ subunit of CT with the viral inoculum resulted in more extensive diffusion of CT from the injection site. An example of the differing extents of diffusion of CT and PRV from the same injection is shown in Figure 1. In this case, which is representative of all of those incorporating the co-injection paradigm $(n=10)$, PRV immunoreactive neurons were confined to a single segment of the MD (Fig. $1 A, C, E$ ), whereas CT immunoreactivity extended into other subdivisions of the MD as well as into adjacent thalamic nuclei (Fig. $1 B, D, F)$.

\section{Temporal analysis and specificity of transynaptic passage of PRV}

Intracerebral injection of PRV produced patterns of neuronal infection consistent with retrograde transneuronal passage of vi- rus from the site of injection, as shown by temporal analysis of viral replication and transport and the co-extensive distribution of PRV- and CT-labeled neurons at sites of first-order projection. We analyzed the distribution of viral infection at various postinoculation intervals as an initial means of determining first- and second-order infections and used the co-injection of a classical tracer (the $\beta$ fragment of CT) to define further the pattern of first-order infection at longer postinoculation intervals. The absence of anterograde viral transport from the site of injection was established by comparing the patterns of infection with the known connectivity of these regions, as shown in previous investigations using conventional tracers. Using this approach, we were unable to demonstrate any evidence of anterograde transport of virus, either from the site of injection or through a multisynaptic circuit. A good example of this can be found in the patterns of infection resulting from injections in the $\mathrm{MD}$, which failed to produce an anterograde transneuronal infection of layers II or III of PFC regions but did produce a retrograde infection of projection neurons in deeper cortical layers (Fig. 2). Furthermore, injections of virus that involved the m-MD resulted in infection of neurons located in the rostral pole of the RTN, which is known to project to the m-MD. Injections into the same region of the RTN failed to induce infection of neurons in the m-MD, which should be expected if the virus were anterogradely transported.

The temporal aspects of viral replication allowed us to distinguish first- and second-order infection in neurons. Continued replication of virus in neurons that projected directly to the injection sites (first-order neurons) eventually produced pathological changes in the neurons and, at the longest postinoculation intervals, such neurons were associated with immunoreactive glia (Fig. $3 E, F$ ). In contrast, neurons in synaptic contact with the initially infected neurons (second-order neurons) exhibited fewer pathological changes (Fig. $3 E, G$ ), because the virus had undergone replication in these neurons for a shorter period of time. Thus, temporal order can be inferred by the degree of pathological changes in the infected neurons and the association of infected glia. The significance of the glial response in maintaining specific transynaptic passage of PRV has been published (Card et al., 1993; Rinaman et al., 1993) and is considered in greater detail in Discussion.

\section{Transport of virus from the MD} $m-M D(\mathrm{n}=8)$

PRV was confined to the m-MD in two animals that survived 49 hr. The injection site in one case $(94-\mathrm{H} 38$; Fig. $3 A, B)$ covered the $\mathrm{m}-\mathrm{MD}$ throughout most of its rostrocaudal extent, whereas in the other animal (94-H39), the injection site was limited to the caudal third of the m-MD. Although the survival times were similar in both animals, the extent of infection was less in the case in which the injection was restricted to the caudal m-MD. Large numbers of infected neurons were observed in the VP in both animals, particularly in the ventral and medial aspects of its rostral extent, at the region bordering the nucleus of the diagonal band of Broca (NDBB) (Fig. 3E,F). Infected neurons were also found in the rostral and intermediate regions of the RTN, but not in its caudal region. All these cells showed signs of advanced viral infection and were associated with infected glia, suggesting that they gave rise to a first-order, direct projection to the m-MD. Labeling in the striatal regions involved only the accumbens shell, predominantly in its caudal aspect (Fig. $3 E, G$ ), as defined by the distribution of calbindin immunoreactivity (Fig. $3 D$ ). A clear temporal organization was observed in the infection of these neurons compared with 

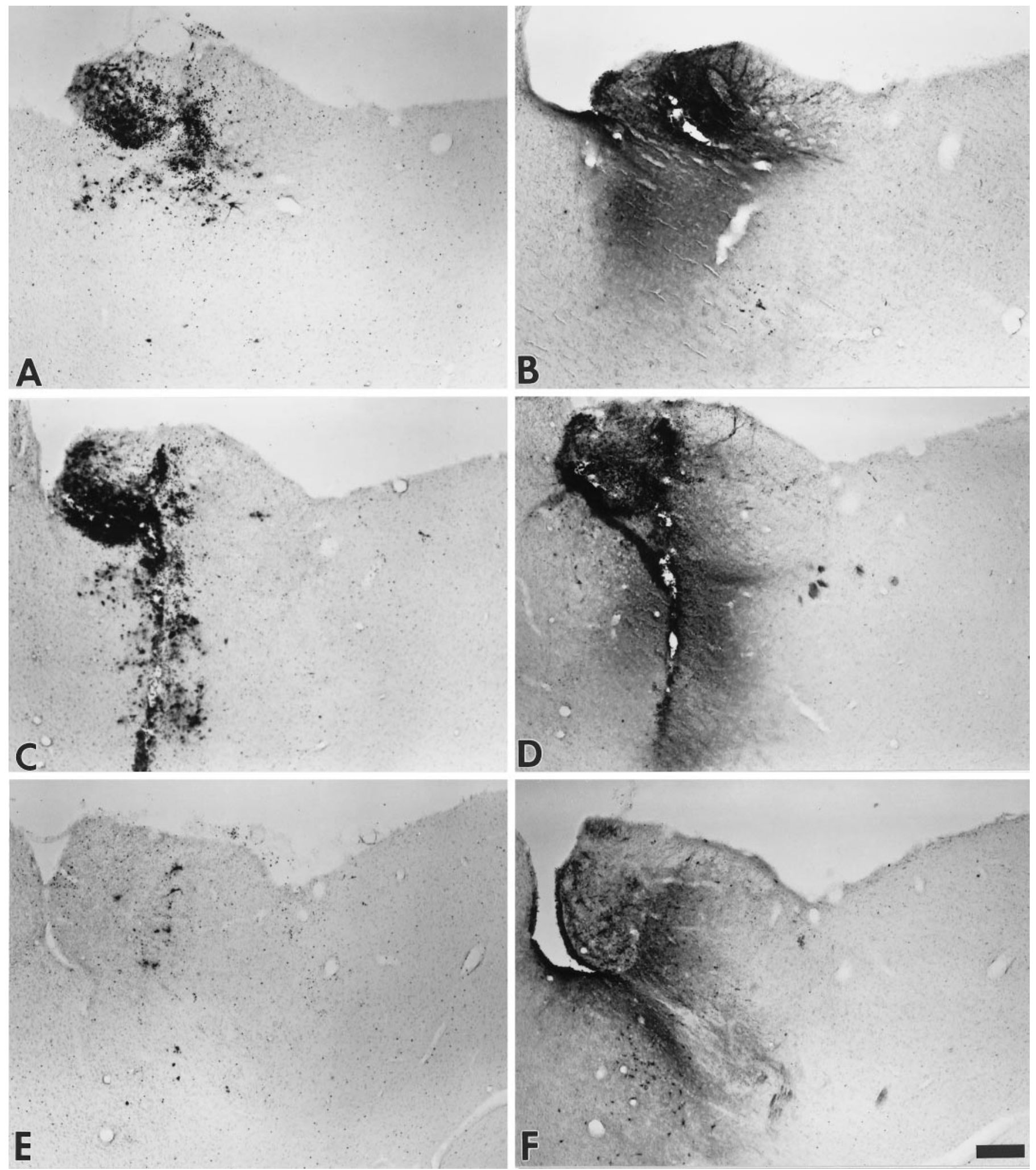

Figure 1. The diffusion of CT and PRV from a common site of injection is illustrated in this figure. The two tracers were mixed in equal parts, and 200 nl was injected into the mediodorsal nucleus $(\mathrm{MDN})$ at $10 \mathrm{nl} / \mathrm{min} . A-F$ illustrate localization of $\mathrm{PRV}(A, C, E)$ or $\mathrm{CT}(B, D, F)$ in adjacent sections through rostral $(A, B)$, intermediate $(C, D)$, and caudal $(E, F)$ levels of the MDN. PRV immunoreactivity is largely confined to the medial region of the MDN in the rostral half of the nucleus, whereas CT exhibits a larger sphere of diffusion throughout the rostrocaudal extent of the MDN. Scale bar (shown in $F$ ): $200 \mu \mathrm{m}$; all figures are of the same magnification. 

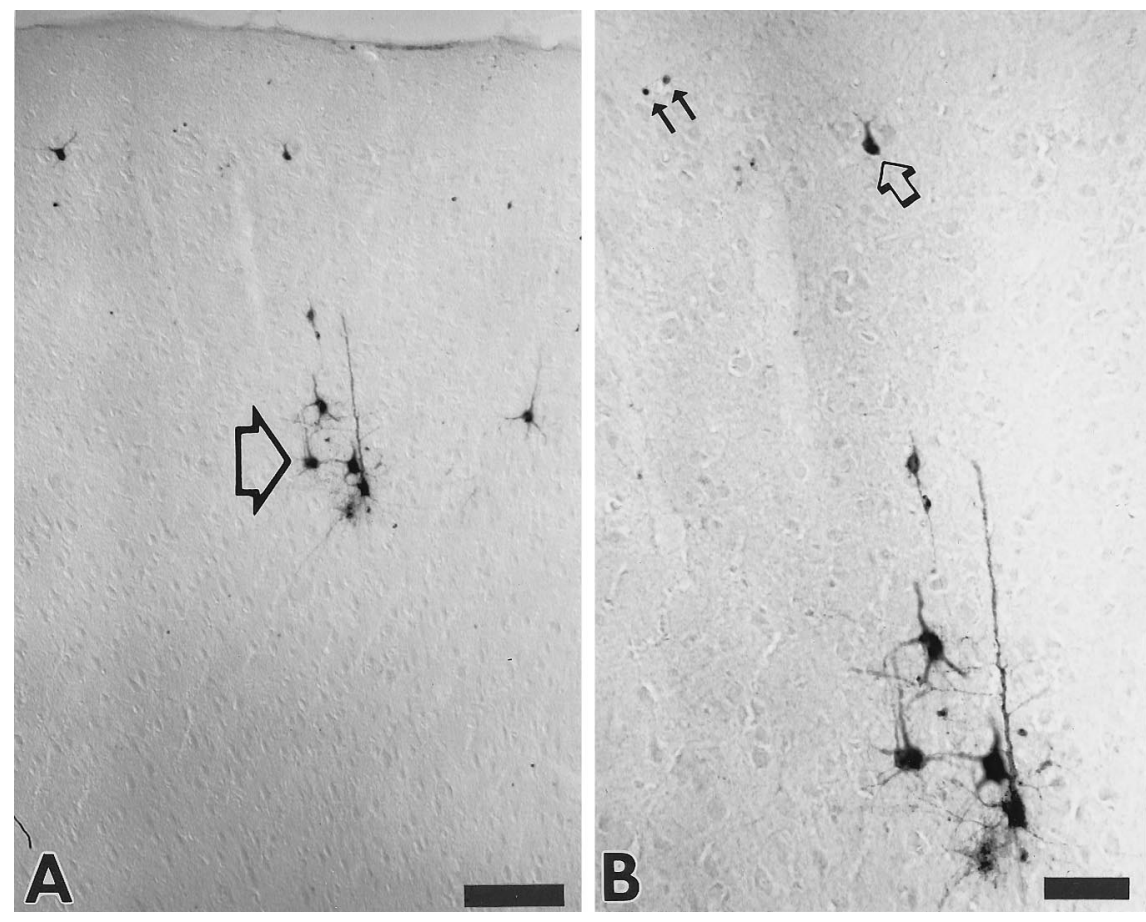

Figure 2. Examination of the cingulate cortex after injection of PRV into the lateral subdivision of the MDN demonstrates that this strain of virus is only transported retrogradely from the site of intracerebral injection. In $A$, the most prominent viral immunoreactivity is present in neurons found in deep layers of the cortex. Densely staining somata and dendrites of these neurons reveal the clear morphological features of pyramidal neurons and also demonstrates that these neurons are in an advanced stage of infection. In contrast, only scattered neurons in an early stage of infection are apparent in superficial layers. In many of these cells, viral immunoreactivity is confined to the cell nuclei $(B$, small arrows), and when it is apparent in the cytoplasm (open block arrow), the staining reveals that the cells are small interneurons rather than projection neurons. These data indicate that retrograde transport of virus from the MDN produced the firstorder infection of pyramidal neurons in deeper layers of cingulate cortex and that transynaptic passage of virus from these cells produced the temporally delayed infection of interneurons in superficial layers. Scale bars: $A, 100 \mu \mathrm{m} ; B, 50 \mu \mathrm{m}$. neurons in the medial VP. Infection of medial VP neurons always preceded infection of shell neurons (compare Fig. 3, $C$ and $E$ ). Similarly, when both populations were infected, neurons in the medial VP always showed signs of more advanced viral replication (Fig. $3 E-G)$. No infected neurons were present in the $\mathrm{CPu}$ and accumbens core of these cases.

Injection in the m-MD also revealed a first-order infection of the RTN. In cases in which the injection site was confined to the $\mathrm{m}-\mathrm{MD}$, we observed a large number of infected neurons in the rostral and intermediate RTN and no infected neurons at caudal levels of the RTN (compare Fig. 4, $A$ and $B$ ). Furthermore, infected neurons in rostral and intermediate regions of the RTN were confined to the ventral third of the nucleus (Fig. 4B).

Several injections that included the m-MD also extended into neighboring regions. Two animals received PRV injections that involved the paraventricular nucleus of the thalamus (PVT) (94H40 and 94-H41). These animals were killed at 39 and 51 hr after injection and, as in the MD injected cases, they contained firstorder infected neurons in the medial VP and rostral RTN and second-order neurons in the shell region of the accumbens. Two additional animals with an injection site that involved the m-MD, PVT, and habenula (cases 94-H22 and 95-H6) exhibited a similar pattern of infection, as seen in other animals in which the injection involved the m-MD along with either the lateral habenula (94-H13) or the anteromedial thalamic nucleus (95-H148). All these cases also exhibited infected neurons consistent with projections to these other thalamic nuclei. For example, cases involving the PVT contained large numbers of infected neurons in the hypothalamic suprachiasmatic nuclei, consistently with the recently demonstrated projection between these nuclei (Moga et al., 1995). In contrast, cases in which the injection was confined to the m-MD did not exhibit infected neurons in the suprachiasmatic nucleus.

\section{$C-M D(\mathrm{n}=5)$}

Five animals received viral injections in regions that included the c-MD and were killed 39 to $52 \mathrm{hr}$ after the viral injection. How- ever, none of the injection sites were actually restricted to this relatively small subdivision. The injection sites covered most of the c-MD and part of 1-MD in two animals (95-H149 and 96-H6) (Fig. $5 A$ ) and most of c-MD and part of m-MD in the other three cases (95-H7, 94-H21, and 96-H5). All of these animals showed advanced infection of a large number of neurons in the polymorph region of the OT (Fig. 5D) as well as in the lateral, subcommissural region of the caudal VP (Fig. $5 E, F$ ). In cases including the 1-MD in the injection site (Fig. $5 A$ ), first-order projection cells were also detected in the GP (Fig. $5 C$ ), and in cases in which the injection also involved the m-MD, cells with advanced infection were detected in the medial, rostral VP. Infection in striatal regions varied according to the extent of the injection site in these cases. We never observed infection of accumbens shell neurons when the injection was restricted to the c-MD and 1-MD (Fig. 5D). When injections involved the c-MD along with either the lateral or medial segments, we observed a limited number of infected core neurons that were found almost exclusively at rostral levels in the core (Fig. 5G). In contrast, when the viral injection was confined to the l-MD, we never observed infected neurons in either of the accumbens regions (see below). A few scattered infected cells at an early stage of infection at the septal border of the shell region of the accumbens, as well as some infected cells in the core region of the accumbens, were found in the cases in which the injection included the m-MD and the c-MD. A few infected cells in the core and the $\mathrm{CPu}$ were observed in the cases in which injections covered both the c-MD and 1-MD.

Cells in the RTN were also infected after injections that included the c-MD (Fig. 5B). The distribution of infected RTN neurons was different depending on the involvement of the m-MD or 1-MD in the injection site. The animals in which PRV was injected in the m-MD and c-MD showed infected neurons in the rostral pole of the RTN, similar to those with an injection selectively placed within the m-MD. On the other hand, injections in the $1-\mathrm{MD}$ and $\mathrm{c}-\mathrm{MD}$ resulted in infection of neurons in more caudal parts of the RTN (Fig. $5 B$ ), similar to that observed after 

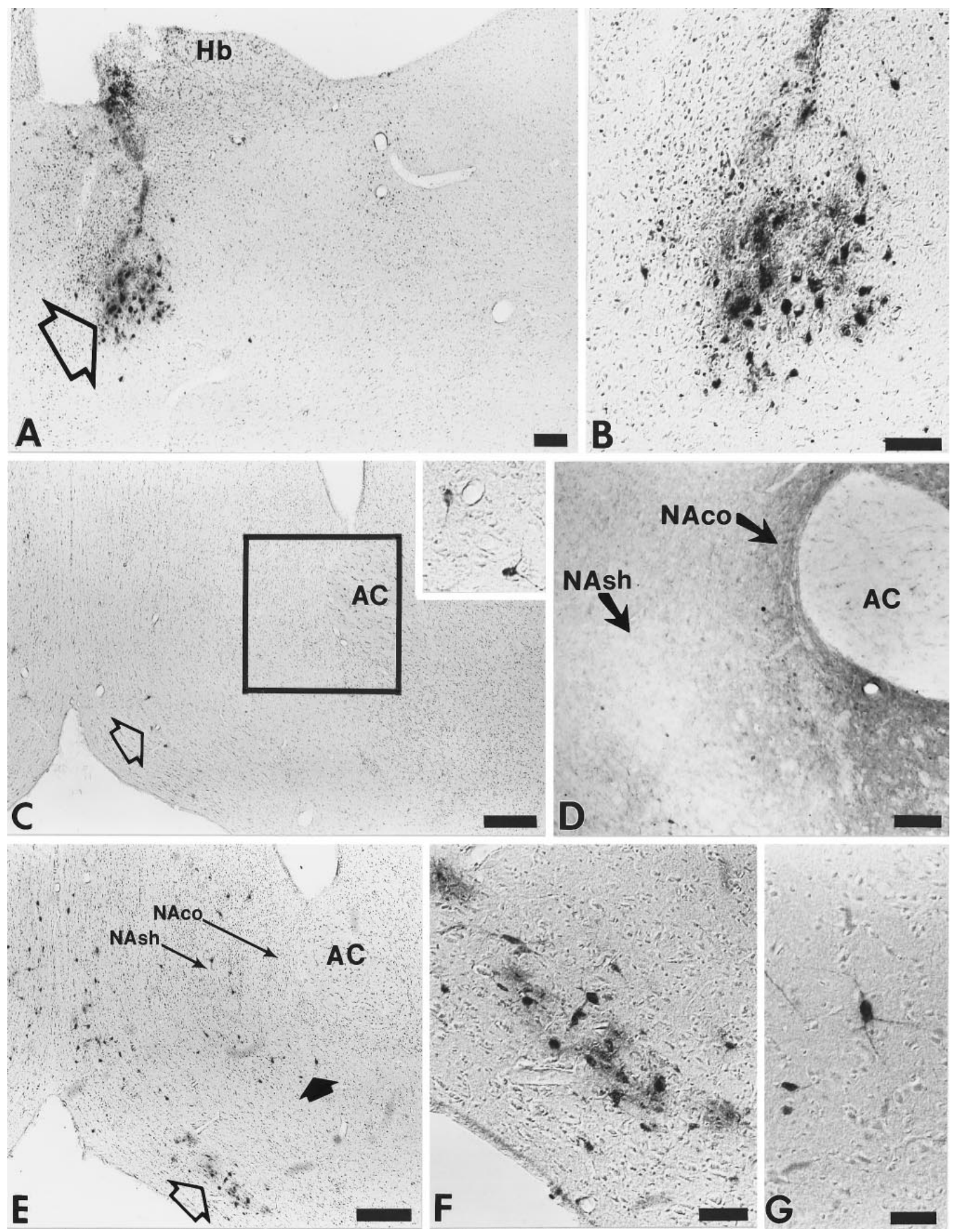

Figure 3. Injection of PRV into the medial segment of the MD nucleus revealed a disynaptic connection with the basal forebrain. $A$ and $B$ demonstrate the restricted injection site resulting from injection of $100 \mathrm{nl}$ of virus at $10 \mathrm{nl}$ per minute. Neurons displaying PRV immunoreactivity are confined to the medial segment of the nucleus with no apparent spread to the central segment or adjacent thalamic nuclei. At short postinoculation intervals, infected neurons were present in the medial/rostral aspect of the VP $(C$, open block arrow, inset $)$ but were not found in either division of the nucleus accumbens. The inset in $C$ illustrates the region that is shown at higher magnification in $D$, in which calbindin immunoreactivity defines the limits of the core ( $N A c o$ ) and shell $(N A s h)$ regions of the nucleus accumbens. With more advanced infection, more infected neurons were apparent in the medial VP, and they exhibited neuropathological changes characteristic of advanced viral replication $(E, F)$. In addition, the virus passed transynaptically to infect neurons in the shell, but not in the core, of the nucleus accumbens $(E, G)$. See text for additional details of the experiments and controls that established the route of viral transport through this circuitry. The area marked by the open and closed block arrows in $E$ are shown at higher magnification in $F$ and $G$, respectively. Scale bars: $A, C, E, 200 \mu \mathrm{m} ; B, D, 100 \mu \mathrm{m} ; F, G$, inset in $C, 50 \mu \mathrm{m}$. 


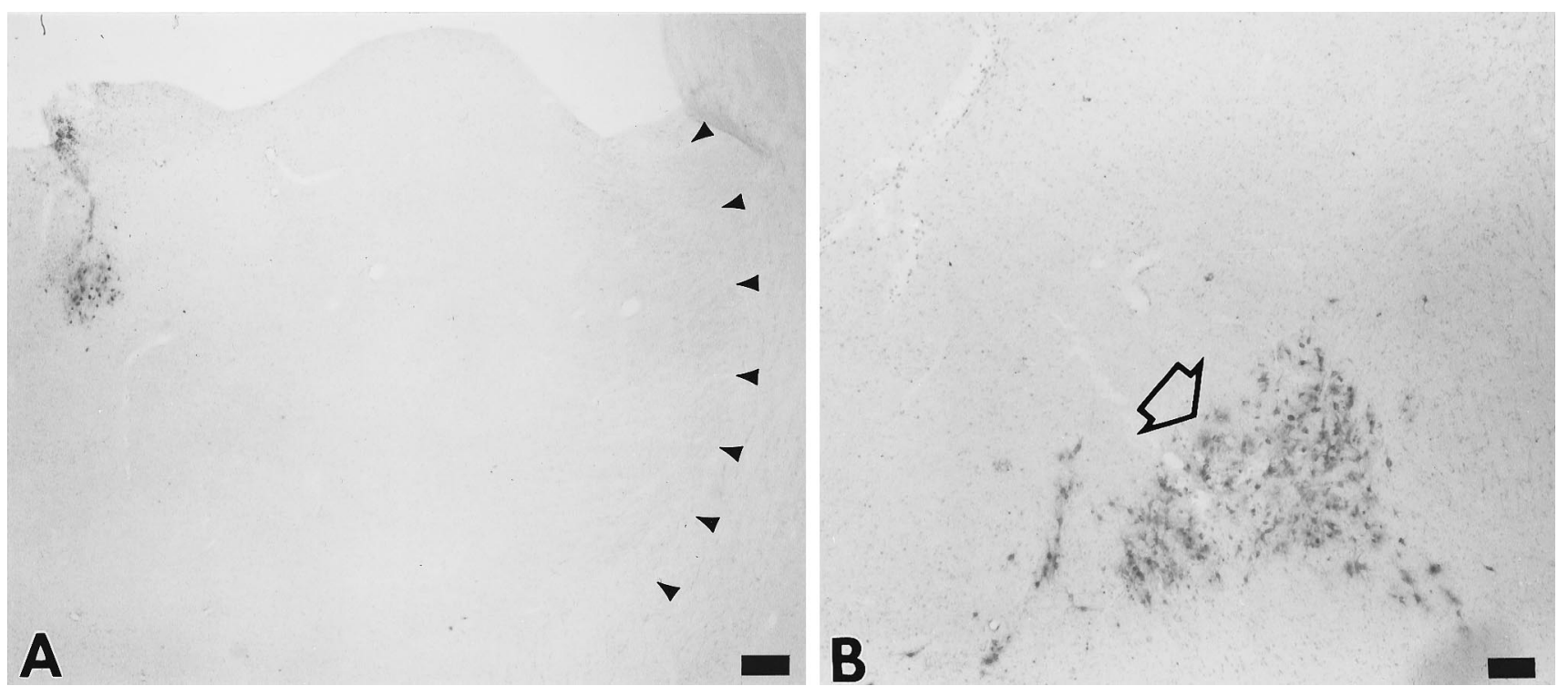

Figure 4. Injection of the m-MD also revealed a topographically organized afferent input from neurons in the RTN. After restricted injections of this subdivision, infected neurons were present in the ventromedial portion of the rostral RTN $(B)$, but were not present in the caudal RTN ( $A$, arrowheads). Scale bars: $A, 200 \mathrm{~mm} ; B, 100 \mathrm{~mm}$.

injections restricted to the l-MD (see below). Thus, these patterns appear to be the result of transynaptic passage after m-MD and 1-MD PRV rather than after c-MD PRV.

\section{$L-M D(\mathrm{n}=5)$}

Five animals received injections within the 1-MD that largely excluded the c-MD. Four animals were examined after survival periods of 44 to $50 \mathrm{hr}$. In one of these cases (94-H18), the injection site encompassed the caudal half of the l-MD, whereas the other two animals (94-H12 and 95-H150) received the PRV injection in the l-MD and the lateral habenula. Infected neurons at an advanced stage were detected in the GP, but no infected cells were seen in the VP. In addition, neurons at an early stage of infection were detected in the $\mathrm{CPu}$ but not in the accumbens. In these cases, cells in advanced stages of infection were also seen in the caudal aspects of the RTN.

Two animals were killed after relatively long survival periods ( $\sim 68 \mathrm{hr})$ that yielded a widespread infection that was extensive across most of the structures studied. The injection site in one of these animals (94-H7) was centered in the caudal third of the 1-MD and extended into the lateral habenula in the other (94-H9). Both animals exhibited infected neurons in the VP at different stages of infection. Several neurons showing signs of advanced infection could be observed in the GP as well. Few scattered infected cells could be observed in both the core and the shell regions of the nucleus accumbens in one case (94-H7), and only in the shell in the other (94-H9). The sparse number of infected neurons in the nucleus accumbens contrasted to the heavy labeling throughout most other structures in these cases.

\section{Control experiments $(\mathrm{n}=8)$}

In two cases, PRV injections were made into the m-MD in rats that had received an electrolytic lesion of the medial VP or the GP. The injection sites in these cases were restricted to the $\mathrm{m}-\mathrm{MD}$. These animals were killed after long incubation periods of 60 and $62 \mathrm{hr}$. In one case with a GP lesion that spared most of the VP (95-H63), neurons at an advanced stage of infection were observed in the medial VP, and neurons earlier in the course of infection were detected in the accumbens shell. In the case with an extensive lesion of the VP (95-H64), PRV injection in the m-MD failed to label neurons in the shell.

Three animals received viral injections in regions adjacent to, but avoiding entirely, the m-MD. In one of the cases, the injection included the medial habenula and the overlying dentate gyrus of the hippocampus (94-H17), and no infected neurons could be detected in striatal or pallidal regions. In another animal (95H11), PRV was injected in the dentate gyrus of the hippocampus, and no viral immunoreactivity was observed in any basal ganglia or thalamic region. A third case received the PRV injection into the lateral septum with spread of virions into the lateral ventricle (95-H78), but no viral infection could be detected in the basal ganglia.

Two additional animals received PRV injections in structures close to, but not in, the 1-MD. In one case (95-H8), PRV was injected into the ventricle. No labeling was found in the basal ganglia in this animal. In another animal (94-H47), PRV was injected in the laterodorsal thalamic nucleus, which is located laterally to the MD. In this case, infected neurons were observed in the septum and NDBB but not in the basal ganglia.

The injection site in another animal encompassed all three segments of the MD (case 95-H9), and the pattern of viral infection was similar to that of the cases of injection in each segment combined. Thus, heavily infected neurons were observed in the medial and lateral VP as well as in the GP, and secondorder neurons were detected in the shell and core regions of the accumbens as well as in the $\mathrm{CPu}$.

\section{Transport of virus from the RTN}

The injection sites that included the RTN were distributed along most of the rostrocaudal axis of this thalamic nucleus. To analyze the results without losing any potential topographic information, the cases were sorted according to the location of the center of injection along the rostrocaudal axis. 


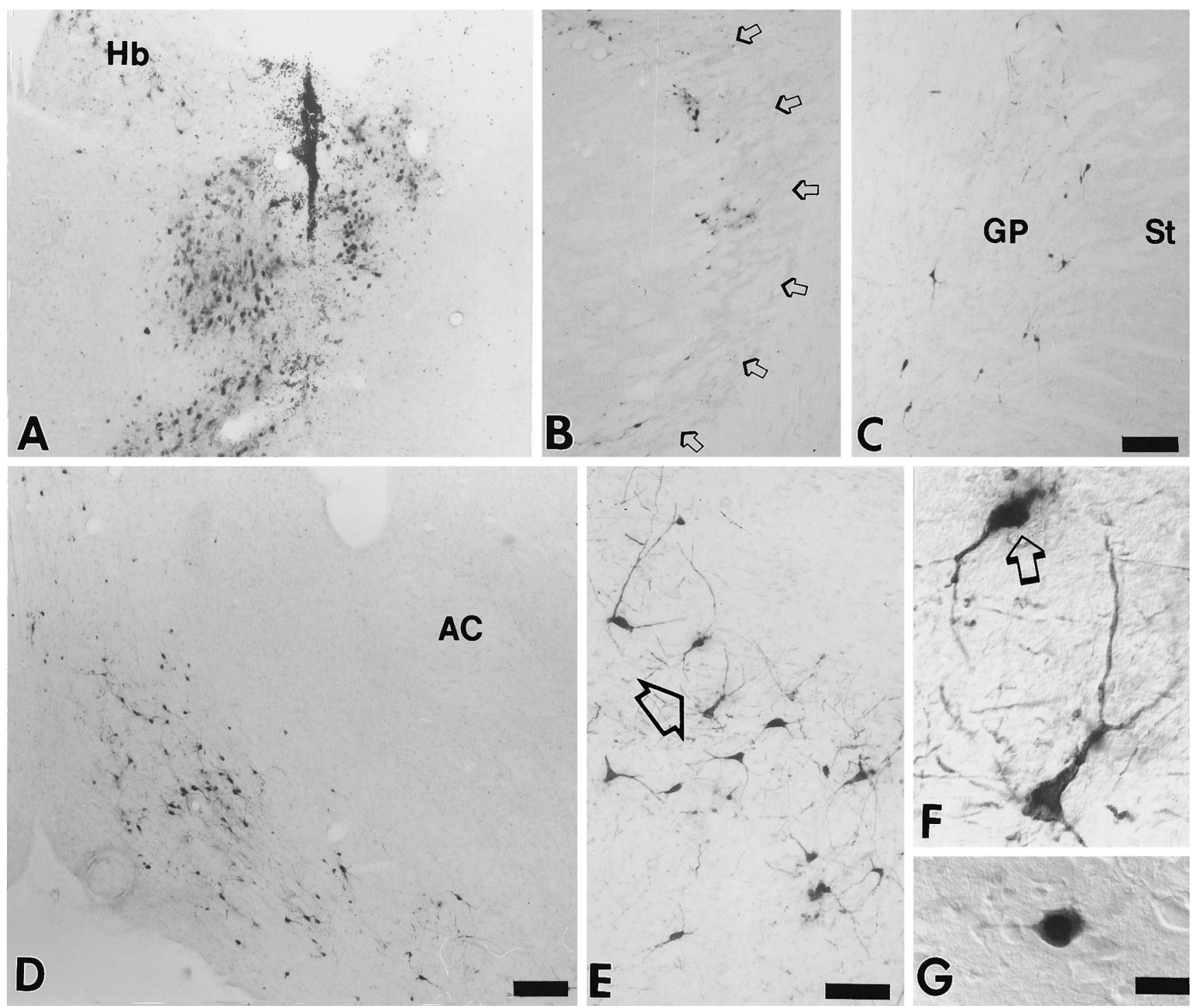

Figure 5. Injections of PRV that involved the c-MD and 1-MD $(A)$ produced a pattern of infection that differed from that produced by injection of virus into the m-MD. Infected first-order neurons were present in the intermediate and caudal RTN $(B)$, the GP, $(C)$, and the lateral VP $(E, F)$. At longer postinoculation intervals, we did not observe transynaptic infection of neurons in the shell of the nucleus accumbens $(D)$, but did observe occasional neurons in the core at rostral levels $(G)$. The cells marked by the open block arrow in $E$ are shown at higher magnification in $F$. The prominent viral immunoreactivity in the somatodendritic compartments of neurons in the GP and VP $(C, E)$ and pathological changes in some of the infected cells $(F$, arrow) indicate that these cells are in an advanced stage of infection. $H b$, Habenula; $G P$, globus pallidus; $S t$, striatum; $A C$, anterior commissure. Scale bars: $A-D$ (shown in $C$ ), $200 \mu \mathrm{m} ; E, 100 \mu \mathrm{m} ; F, G$ (shown in $G$ ), $20 \mu \mathrm{m}$.

\section{Rostral RTN ( $\mathrm{n}=2)$}

Two animals received PRV injections in the rostral pole of the RTN and were killed 48 and $50 \mathrm{hr}$ after the injection. The injection site included the ventral aspect of the rostral RTN in one case (94-H45; Fig. 6A), in the same region of the RTN that showed infection after m-MD injections. In this case, neurons at a comparatively advanced stage of infection were observed in the medial/rostral VP (Fig. $6 F$ ) as well as in the lateral and caudal aspects of the VP (Fig. 6B). Also, scattered neurons very early in their infection were observed in both the accumbens core and shell (Fig. $6 F, G$ ). The other animal (case 95-H143) received the PRV injection into the ventral and dorsal aspects of the RTN rostral pole. In this case, first-order projection neurons were observed in the lateral and caudal VP as well as in the GP.
Neurons at an early stage of infection were detected in the accumbens core and $\mathrm{CPu}$. No infected cells were found in the accumbens shell in any of these cases. In the animal injected in the ventral aspect of the rostral RTN, neurons advanced in infection were detected in the c-MD but not in the m-MD. In the other, more extensively injected, case, heavily infected neurons were detected in the c-MD and 1-MD (Fig. 6C-E).

\section{Intermediate RTN $(\mathrm{n}=2)$}

Two cases were injected in the intermediate region of the RTN. In one of them (95-H145), neurons advanced in infection were observed in the medial and rostral VP and in the m-MD. The distribution of first-order projection neurons was matched by CT immunoreactivity in this animal (see Fig. 10). Neurons at an early 

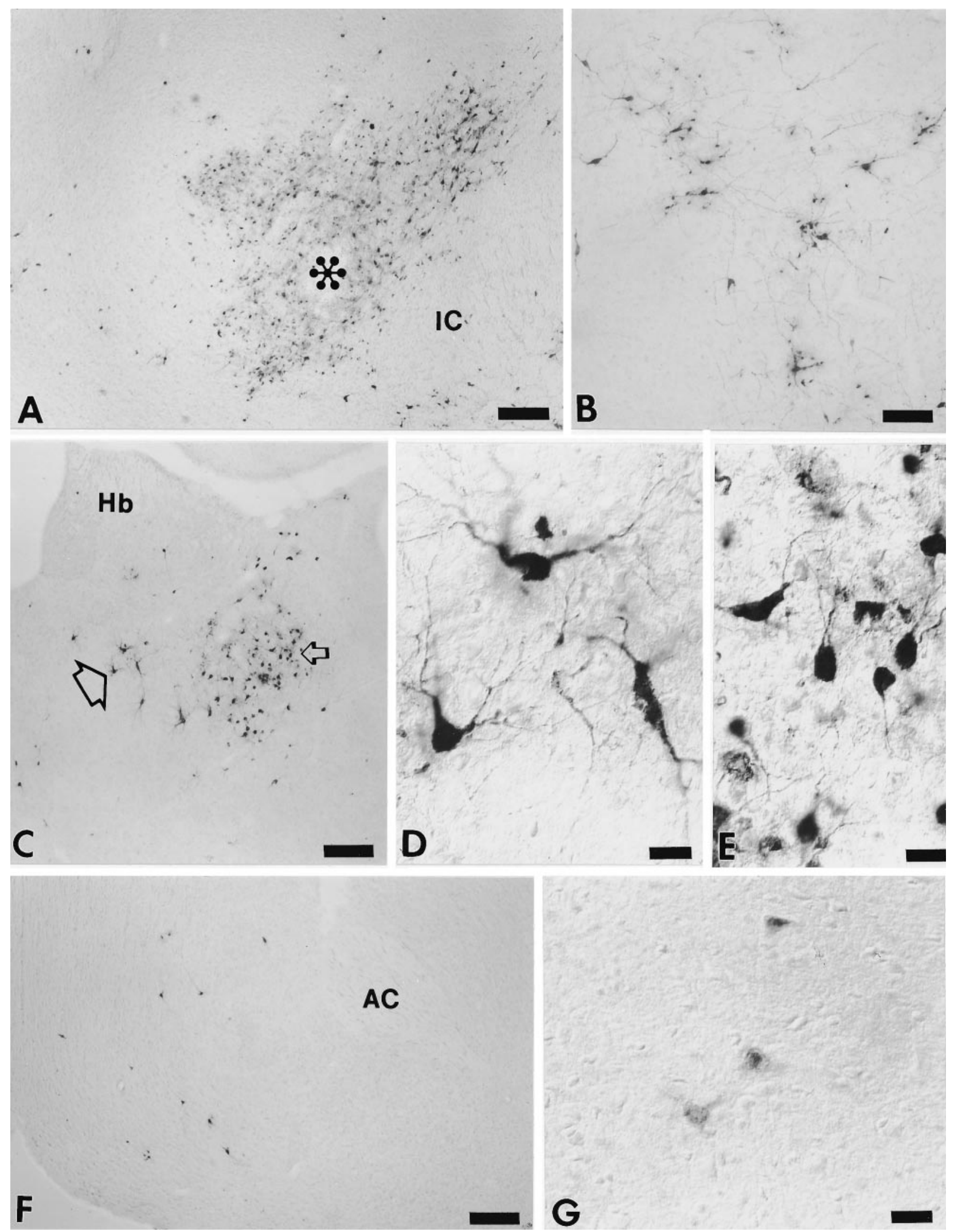

Figure 6. Injection of PRV into the rostral and ventral portion of the RTN $(A)$ labeled elements of the MD and basal forebrain circuitry revealed by injection of virus into the 1-MD (compare with Fig. 5). The center of the injection site is marked by the asterisk in $A$. Retrogradely infected first-order neurons were observed in the lateral portion of the VP $(B)$ as well as in the c-MD and l-MD $(C)$. The morphology of the neurons marked by the large and small open block arrows in $C$ are shown at higher magnification in $D$ and $E$, respectively. Transynaptic infection of small numbers of neurons was apparent in the medial VP and nucleus accumbens shell $(F)$ as well as in the rostral portion of the core $(G)$. Scale bars: $A, C, F, 200 \mu \mathrm{m} ; B, 100 \mu \mathrm{m} ; D$, $E, 20 \mu \mathrm{m}$. 


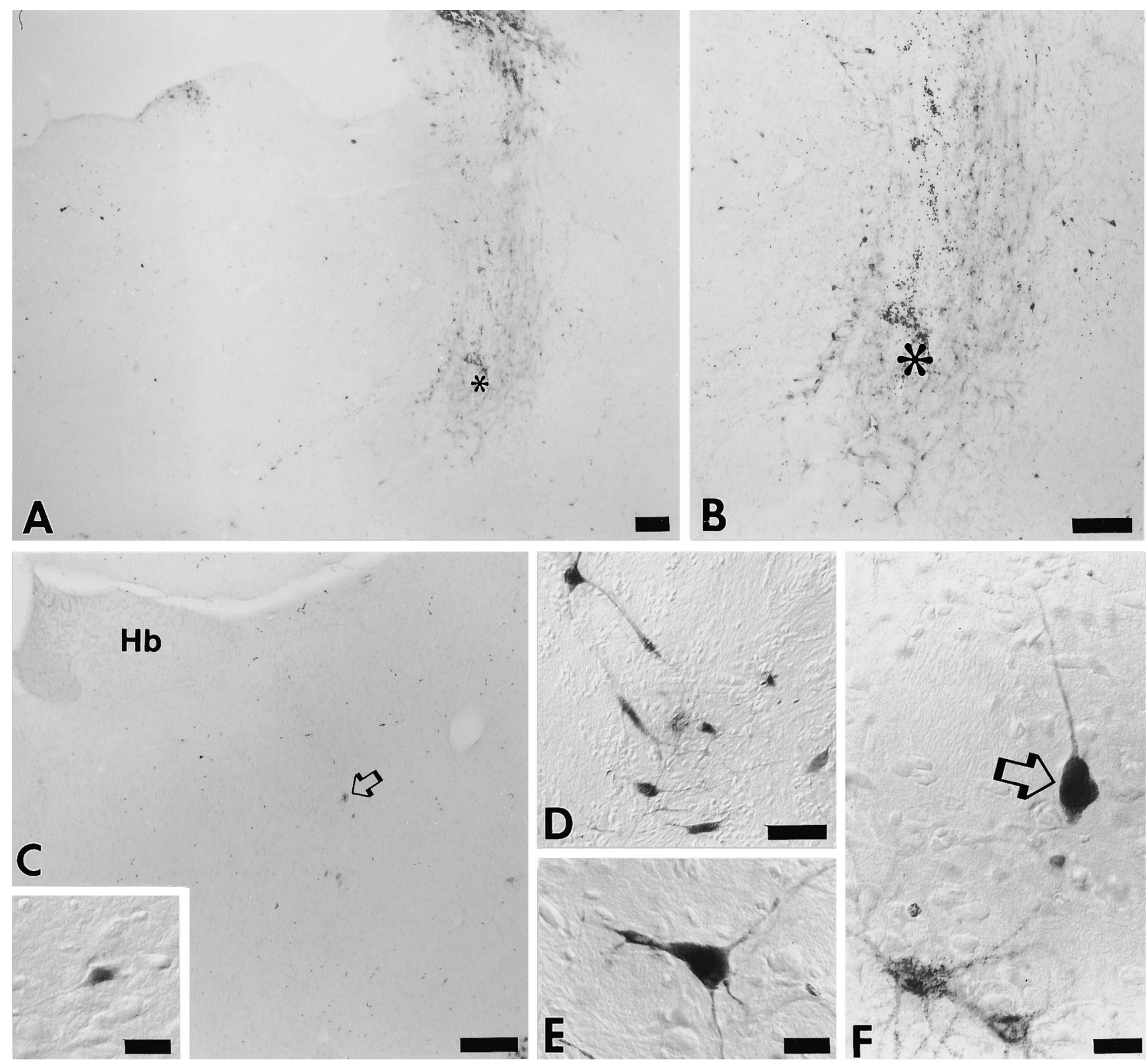

Figure 7. Injection of virus into the caudal RTN produced a pattern of infection distinct from that produced by injection of the rostral RTN. The site of injection is illustrated in $A$ and $B$, with the asterisks marking the position of the tip of the injection cannula. Scattered infected first-order neurons were present in the l-MD $(C)$; the neuron marked by the open block arrow in $C$ is shown at higher magnification in the inset. Larger numbers of first-order neurons were present in the GP $(D, E)$. At longer survival times, striatal medium spiny neurons were heavily infected $(G$, bottom of field), and we also noted viral immunoreactivity in large spiny interneurons of the striatum that exhibited a morphology similar to that of cholinergic interneurons $(F$, open block arrow). The appearance of viral immunoreactivity in these cells at long survival intervals is consistent with them becoming infected by retrograde transynaptic passage of virus from the medium spiny neurons. No infected neurons were observed in either the core or the shell of the nucleus accumbens in these animals. Scale bars: $A-C, 200 \mu \mathrm{m} ; D, 50 \mu \mathrm{m} ; E, F$, inset in $C, 20 \mu \mathrm{m}$.

stage of infection were detected in the accumbens shell. In the other case (95-H75), which received the PRV injection at a more dorsal location within the intermediate RTN, no viral infection could be found in any pallidal or striatal region.

\section{Caudal RTN (n = 4)}

Four animals received the PRV injection at caudal locations within the RTN. Two of these animals received the injections at 2.0-2.5 mm caudal to bregma. In one of them (case 94-H46), the injection site was tightly confined to the RTN (Fig. $7 A, B$ ), and no detectable infection was observed in the accumbens or VP. The other case with a similar injection site (95-H12) extending medially into the VPL thalamic nucleus did not result in viral infection in the accumbens or VP. However, both cases exhibited a large number of neurons advanced in infection within the GP (Fig. $7 D, E)$ and some infected neurons in the l-MD (Fig. 7C). Cells in early stages of infection were detected in the $\mathrm{CPu}$ (Fig. $7 F$ ). In two other animals, the injection site was placed at even more caudal locations within the RTN; i.e., 3.0 or $3.3 \mathrm{~mm}$ caudal to bregma. In these cases (95-H76 and 95-H146), no infected cells were labeled in any region within the basal ganglia. 


\section{Control injections for the RTN ( $\mathrm{n}=7)$}

A group of animals received PRV injection in the vicinity of the RTN rostral pole but without including the RTN. Three cases involved the bed nucleus of the stria terminalis (BNST) rostral to the RTN (cases 94-H44, 94-H49, and 94-H51). In these cases, neurons at an advanced stage of infection were detected in the medial and rostral VP, and neurons with early infections were seen in the accumbens shell, but not in the core, which is a different pattern from that of rostral RTN injections. In two additional animals (cases 94-H48 and 95-H14), the injection sites were restricted to the internal capsule with a little involvement of the GP in one, just lateral to where the rostral RTN injections were placed. Although widespread infection was seen throughout most of the neocortex in those cases in which tissue damage was present at the injection sites, no infected neurons were detected in the accumbens or VP. In the case in which the GP was included in the injection site, however, heavily infected cells were detected in the $\mathrm{CPu}$.

Two animals received PRV injection in regions adjacent to the caudal RTN. One of them received the viral injection in the lateral geniculate nucleus and dentate gyrus of the hippocampus (case 95-H13). In this animal, neurons advanced in infection were observed in the dorsomedial hypothalamus but not in the basal ganglia. Another animal (case 95-H77) received the injection in the internal capsule, in a site located laterally to that of the caudal RTN injection cases. In this animal, no evidence of infected neurons was observed in the basal ganglia, although extensive labeling was detected in most cortical regions.

\section{Other circuits labeled after MD and RTN injections}

The cortical regions retrogradely infected after PRV injections in the MD also differ according to the segment injected. Thus, injections in the m-MD resulted in viral infection in the infralimbic, medial orbital, and agranular insular cortices. In the cases in which the injection sites included the c-MD, neurons advanced in infection were detected in orbital and PL cortices. In addition, selective injections in the l-MD resulted in first-order infected neurons in the piriform and cingulate cortices. Injections in the rostral RTN resulted in infected neurons in cingulate and PL cortices, whereas injections in the caudal RTN labeled the cingulate cortex.

In addition to structures in the basal ganglia, basal forebrain, and cortex, a number of other brain regions exhibited viral immunoreactivity after PRV injections in the different divisions of the MD or RTN. These were different for each of the regions studied, and they were consistent with previously reported data using conventional tract tracing techniques. The brain regions in which we observed neurons with advanced infection (first order) and neurons with early stages of infection (second order) are listed in Tables 1 and 2. Briefly, injections in the m-MD resulted in viral infection in NDBB, VTA, and laterodorsal tegmental nucleus (LDTg) (Fig. 8). In the cases in which the injections sites extended into the PVT, cells at an advanced stage of infection were also found in the suprachiasmatic nucleus and dorsomedial hypothalamus. In the cases in which the injection sites included the c-MD, neurons advanced in infection were detected in the lateral septum, OT, NDBB, and LDTg (Fig. 9). In the cases injected in the l-MD, infected neurons were seen in lateral septum, NDBB, raphe magnus, substantia nigra pars reticulata, and LDTg (Fig. 10).

Injections in the rostral RTN resulted in infected neurons at a relatively advanced stage in the medial nucleus of the amygdala,
SI, NDBB, septum, VPL and VPM thalamic nuclei, pedunculopontine nucleus, LDTg, and contralateral RTN (Fig. 11). Injections in the intermediate RTN labeled the m-MD and LDTg (Fig. 12). Also, injections in the caudal RTN resulted in advanced neuronal infection in the medial nucleus of the amygdala, SI, BNST, VPL-VPM thalamic nuclei, and SNc (Fig. 13).

\section{DISCUSSION}

An important issue in correlating the anatomy of the limbic system with psychiatric disorders lies in the specificity of connections among key components of these systems. Although studies using sequential labeling of retrogradely transported compounds have been powerful in assessing such connections, the existence of several multisynaptic pathways presents unique constraints that render such an approach problematic. For this reason, we used PRV for tracing transynaptic projections from the core and shell regions of the nucleus accumbens to the VP and thalamus. The affinity of the virus for axon terminals and astrocytes (Vahlne et al., 1978, 1980; Marchand and Schwab, 1986) permits discrete injections of subfields in the thalamic target nuclei; only the VP cells projecting to the injection site will become infected by retrograde transport of virus, and furthermore, only accumbens neurons that specifically synapse with the retrogradely infected VP cells will exhibit transynaptic and second-order infection. In this way, we can determine with confidence the specificity of accumbens output projections to the VP and thalamus.

\section{Specificity of viral labeling}

Controlled intracerebral injection of PRV into the MD or RTN produced highly restricted cell labeling at the site of injection that was confined to the subdivisions of the MD or RTN in many cases. This technique has been used previously to assess the central neural connections labeled after injections of virus into peripheral structures (for review, see Card and Enquist, 1994; Loewy, 1995; Mettenliter, 1995; Enquist and Card, 1996). However, because this study used intracerebral injections, one issue that should be carefully addressed is the potential of the virus to diffuse away from the injection site and infect neighboring cells, an event that may confound interpretation. We were able to control for such a possibility by using animals in which the injections were made into structures surrounding, but not including, the MD and RTN. The remarkable differences in labeling between MD/RTN injections and these controls argue strongly against the possibility that the results may be confounded by the diffusion of virus into the area surrounding the injection site. Thus, structures such as the VP or NDBB that were consistently labeled after MD/RTN injections were not infected after injections in the septum, BNST, internal capsule, or habenula. The results clearly show that injections confined to the medial, c-MD, or 1-MD infect restricted sets of afferent sources, suggesting that there is little, if any, spread of virus onto the neighboring MD segments. Therefore, PRV-Bartha can be used effectively as a specific transynaptic tracer in the CNS.

The direction of viral transport was an important consideration in interpreting our findings. Zemanick and colleagues (1991) have reported differential transport of two strains of HSV from the primate motor cortex after intracerebral injection, with one strain passing only in an anterograde transynaptic direction and the other exclusively in a retrograde transynaptic direction. In preliminary studies (Enquist et al., 1993), we also observed differential transport of two strains of PRV injected into the rat PFC. Wildtype virus was transported in both directions (anterograde and retrograde) from the injection site, whereas the attenuated PRV- 
Table 1. Brain regions showing labeling after PRV injections in different regions of the MD thalamic nucleus

\begin{tabular}{|c|c|c|c|c|}
\hline & m-MD & $\mathrm{c}-+\mathrm{m}-\mathrm{MD}$ & $1-+\mathrm{c}-\mathrm{MD}$ & 1-MD \\
\hline \multicolumn{5}{|l|}{ Forebrain } \\
\hline \\
\hline Agranular insular cortex & 1 & & & \\
\hline Cingulate cortex & & $1^{*}$ & $1^{*}$ & 1 \\
\hline Entorhinal cortex & & & & 1 \\
\hline Infralimbic prefrontal cortex & 1 & $1^{*}$ & & \\
\hline Orbital cortex & 1 & $1^{*}$ & * & \\
\hline Prelimbic prefrontal cortex & & 1* & $1^{*}$ & \\
\hline Claustrum & & $1^{*}$ & $1^{*}$ & 1 \\
\hline \multicolumn{5}{|l|}{ Olfactory cortex } \\
\hline Anterior olfactory nucleus & & 2 & $1^{*}$ & \\
\hline Olfactory tubercle (polymorph region) & & $1^{*}$ & $1^{*}$ & \\
\hline Islands of Calleja & & 2 & 2 & \\
\hline Piriform cortex & 2 & 2 & 2 & 1 \\
\hline \multicolumn{5}{|l|}{ Hippocampal formation } \\
\hline Subiculum, ventral & 1 & & & \\
\hline $\mathrm{CA} 1 / \mathrm{CA} 2$ & 2 & 2 & & 2 \\
\hline \multicolumn{5}{|l|}{ Amygdala } \\
\hline Medial nucleus & & & * & 2 \\
\hline Cortical nucleus & 2 & & & 1 \\
\hline Basolateral nucleus & & & 2 & 2 \\
\hline \multicolumn{5}{|l|}{ Septal region } \\
\hline Lateral septal nucleus & 1 & $1^{*}$ & $1^{*}$ & 1 \\
\hline Medial septal nucleus & 1 & $1^{*}$ & $1^{*}$ & \\
\hline Nucleus of the diagonal band of Broca & 1 & $1^{*}$ & $1^{*}$ & 1 \\
\hline Bed nucleus of the stria terminalis & 2 & $1^{*}$ & 2 & 2 \\
\hline \multicolumn{5}{|l|}{ Basal ganglia } \\
\hline Caudate-putamen & & & 2 & 2 \\
\hline Accumbens core & & 2 & 2 & \\
\hline Accumbens shell & 2 & 2 & & \\
\hline Ventral pallidum (rostral/medial) & 1 & $1^{*}$ & $1^{*}$ & \\
\hline Ventral pallidum (caudal/lateral) & & $1^{*}$ & $1^{*}$ & \\
\hline Globus pallidus & & & $1^{*}$ & 1 \\
\hline Entopeduncular & & & 2 & 1 \\
\hline Fundus striatum & & & $1^{*}$ & \\
\hline \multicolumn{5}{|l|}{ Thalamus } \\
\hline AV nucleus & & & 2 & \\
\hline Intergeniculate leaf & & 2 & 2 & 2 \\
\hline Centromedian-parafascicular & & 2 & 2 & \\
\hline Habenula, medial & & & 2 & 2 \\
\hline Reticular thalamic nucleus, rostral & 1 & $1^{*}$ & $1^{*}$ & 1 \\
\hline Reticular thalamic nucleus, intermediate & & $1 *$ & $1^{*}$ & 1 \\
\hline Reticular thalamic nucleus, caudal & 1 & 1 & 1 & 1 \\
\hline Zona incerta & 2 & 2 & 2 & 1 \\
\hline Subthalamic nucleus & & & & 2 \\
\hline \multicolumn{5}{|l|}{ Hypothalamus } \\
\hline Preoptic area & 1 & $1^{*}$ & $1^{*}$ & 1 \\
\hline Suprachiasmatic nucleus & & & 2 & \\
\hline Dorsomedial hypothalamus & 2 & & & 2 \\
\hline Ventromedial hypothalamus & 1 & $1^{*}$ & $1^{*}$ & \\
\hline Lateral hypothalamus & 2 & $1^{*}$ & $1^{*}$ & 2 \\
\hline Arcuate nucleus & 2 & 2 & & \\
\hline \multicolumn{5}{|l|}{ Brainstem } \\
\hline Superior colliculus & & & & 1 \\
\hline Pretectal area & & 2 & 2 & \\
\hline Spinal trigeminal nucleus & & & & 2 \\
\hline Nucleus of the solitary tract & 1 & & & \\
\hline Parabrachial & 2 & $1^{*}$ & $1^{*}$ & 1 \\
\hline Area postrema & 2 & & & \\
\hline Laterodorsal tegmental nucleus & 1 & $1^{*}$ & $1^{*}$ & 1 \\
\hline Substantia nigra, pars compacta (A9) & 2 & 2 & 2 & 2 \\
\hline Substantia nigra, pars reticulata & & & & 1 \\
\hline Retrorubral formation (A8) & & & 2 & 2 \\
\hline Ventral tegmental area (A10) & 1 & $1^{*}$ & $1^{*}$ & 2 \\
\hline Raphe magnus & & & $1^{*}$ & 1 \\
\hline Dorsal raphe & 1 & $1^{*}$ & & 2 \\
\hline Locus coeruleus & 2 & & & 1 \\
\hline Periacqueductal gray & 2 & $1^{*}$ & $1^{*}$ & 1 \\
\hline (A5) 1 & & & & 2 \\
\hline Nucleus Darkschewitz & & & & 2 \\
\hline Vestibular nucleus, lateral & & & & 2 \\
\hline
\end{tabular}

1, Cells labeled by direct retrograde transport; 2 , second-order retrograde labeling, after transynaptic passage; *presence of neurons with CT immunoreactivity. 
Table 2. Brain regions showing labeling after PRV injections in different RTN regions

Forebrain

Isocortex

Agranular insular cortex

Cingulate cortex

$1 *$

Entorhinal cortex

Infralimbic prefrontal cortex

Orbital prefrontal cortex

Perirhinal cortex

Prelimbic prefrontal cortex

Claustrum

Olfactory cortex

Olfactory tubercle

Piriform cortex

Endopiriform nucleus

Hippocampal formation

Subiculum, dorsal

Amygdala

Medial nucleus

Basolateral nucleus

Cortical nucleus

Septal region

Lateral septal nucleus

Medial septal nucleus

Nucleus of the diagnoal band of Broca

Bed nucleus of the stria terminalis

Basal ganglia

Caudate-putamen

Accumbens core

Accumbens shell

Ventral pallidus (rostral/medial)

Ventral pallidus (caudal/lateral)

Globus pallidus

Entopeduncular

Substantia innominata

Thalamus

AD nucleus

Mediodorsal, medial segment

Mediodorsal, central segment

VA-VL

VPL-VPM

Intergeniculate leaf

Centromedian-parafascicular

Zona incerta

Subthalamic nucleus

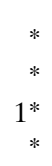

2

2
1

Hypothalamus

Preoptic area

Dorsomedial hypothalamus

2

2

$1 *$

$1 *$

Ventromedial hypothalamus

Lateral hypothalamus

Brainstem

Parabrachial

Laterodorsal tegmental nucleus

Pedunculopontine

Substantia nigra, pars compacta (A9)

Retrorubral field (A8)

Ventral tegmental area (A10)

Dorsal raphe

Periacqueductal gray

$1 *$

$\begin{array}{ll} & 1 \\ 2 & 1 \\ 1^{*} & 1 \\ 1^{*} & 1\end{array}$

$1^{*}$

$1^{*}$

1*

$1 *$

$1 *$

2

2

$1^{*}$

$1^{*}$

$1^{*} \quad 1^{*}$

$1^{*}$

1 *

$1^{*}$

2

$1 *$
1

1

1

1

1

1

2

2

1

1

1* 1

1

1, Cells labeled by direct retrograde transport; 2, second-order retrograde labeling, after transynaptic passage; *neurons immunoreactive for CT. 

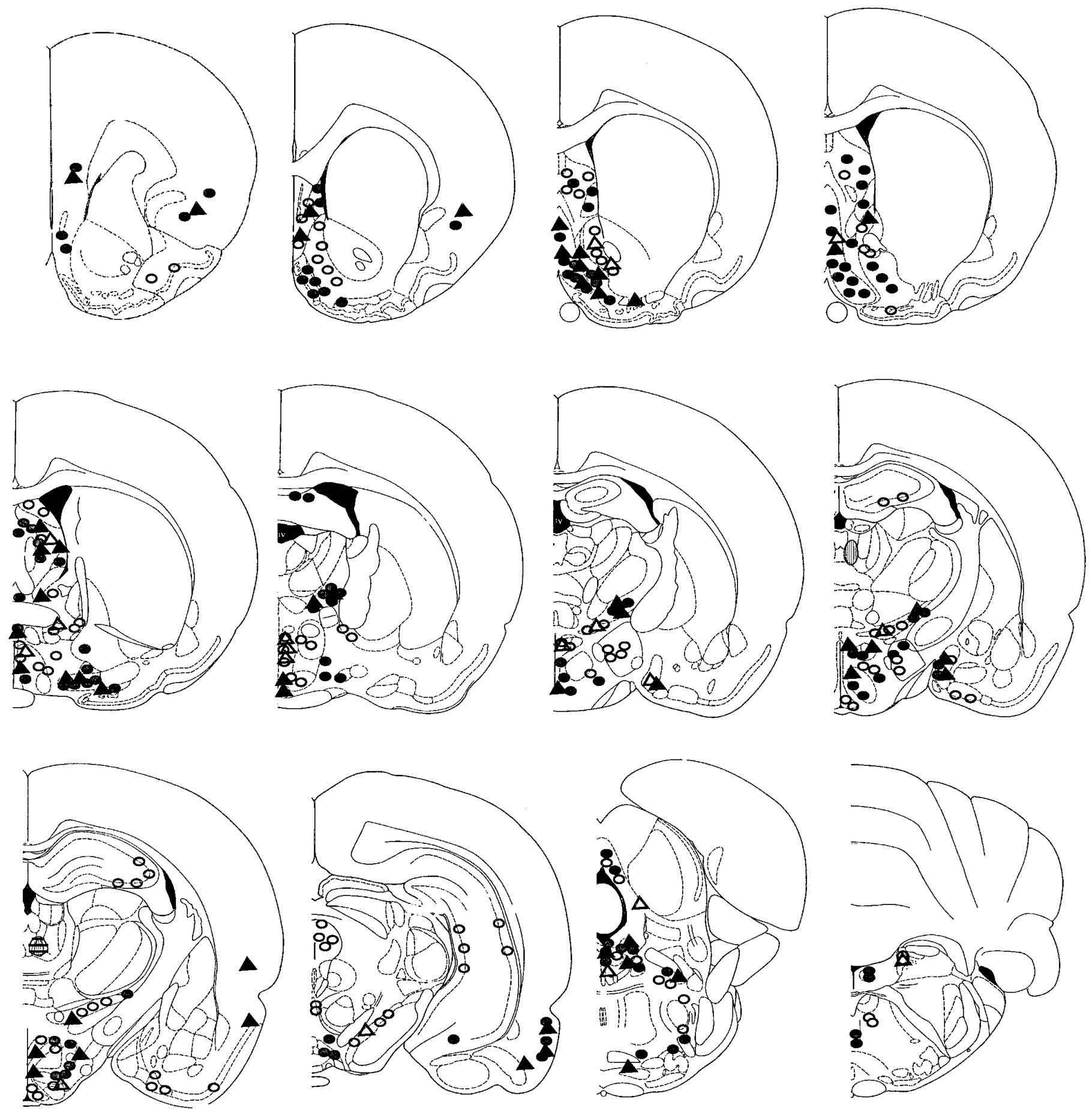

Figure 8. PRV injection in the m-MD resulted in a consistent pattern of infection across structures. Symbols represent infected neurons and their placement in 12 representative drawings of coronal sections of the rat brain, modified from a stereotaxic rat brain atlas (Paxinos and Watson, 1986). The injection sites of two cases are represented with hatched areas, and the results from each animal are shown with different symbols (circles, data from injection shown as vertical hatch; triangles, data from injection shown as horizontal hatch). Solid symbols represent the location of first-order projection neurons, and open symbols show the distribution of second-order projection neurons.

Bartha strain only moved in a retrograde transynaptic manner. The results of the present study support the unidirectional retrograde passage of PRV-Bartha after intracerebral injection and demonstrate the utility of this virus for defining multisynaptic circuitry. The mechanisms that lead to the restricted transport of PRV-Bartha compared with wild-type virus remain to be estab- lished, but may be related to the deletions of envelope glycoprotein genes known to characterize this strain (Enquist, 1994).

A potential source of concern relates to whether viral uptake by fibers of passage may have confounded our results. As mentioned above, the virus has a high affinity for axon terminals and astrocytes. Thus, if substantial tissue damage is avoided at the injection 

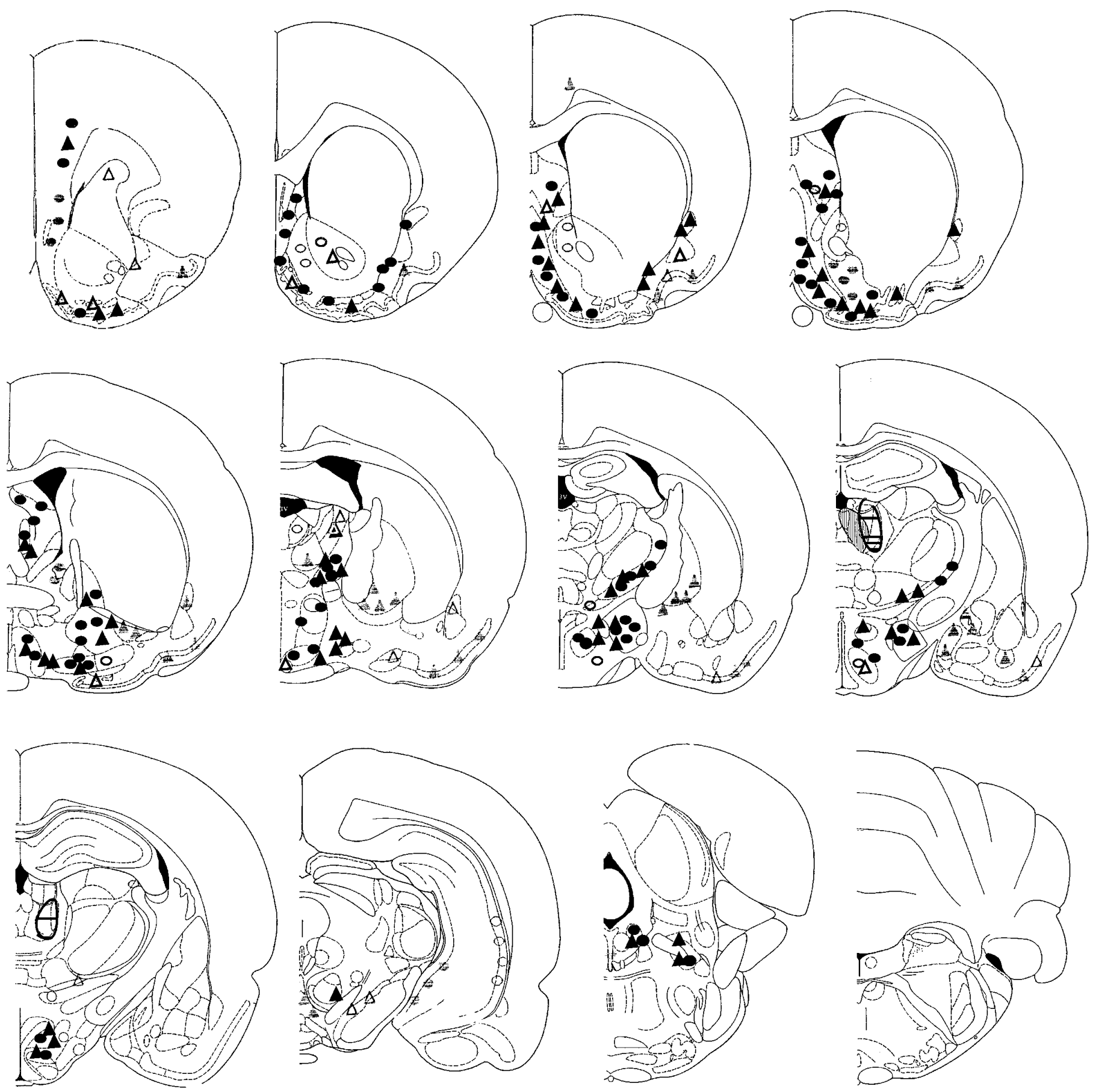

Figure 9. Injection of virus that included the c-MD exhibited infection of some common structures. Symbols represent the distribution of infected neurons after injection of PRV in selected cases. Circles show the distribution of infection after an injection including both the m-MD and the c-MD (injection site shown with vertical hatch). Triangles represent the distribution of infected neurons after an injection that included both the c-MD and the l-MD (injection site represented with horizontal hatch). The distribution of infection in structures labeled in both cases is shown in bold; the distribution of infection observed in any of the cases but not on the other is shown in gray.

site, virions are not likely to enter intact fibers of passage. Our cases involving internal capsule injections show widespread cortical infection. However, these were designed to test whether the spread of virus beyond the injection site could account for any of our results; and furthermore were provided by exceedingly large injections coupled with long survival times. Thus, the presence of tissue damage in the internal capsule in cases with long incubation periods did indeed result in viral uptake and cortical infection, but nonetheless did not result in infection in the VP. Furthermore, none of the cases involving MD- or RTN-selective injections that were included in the results exhibited signs of tissue damage in the injection sites.

\section{First- and second-order projection neurons}

The morphology of infected neurons allowed us to identify firstand second-order projection neurons. First-order neurons are 

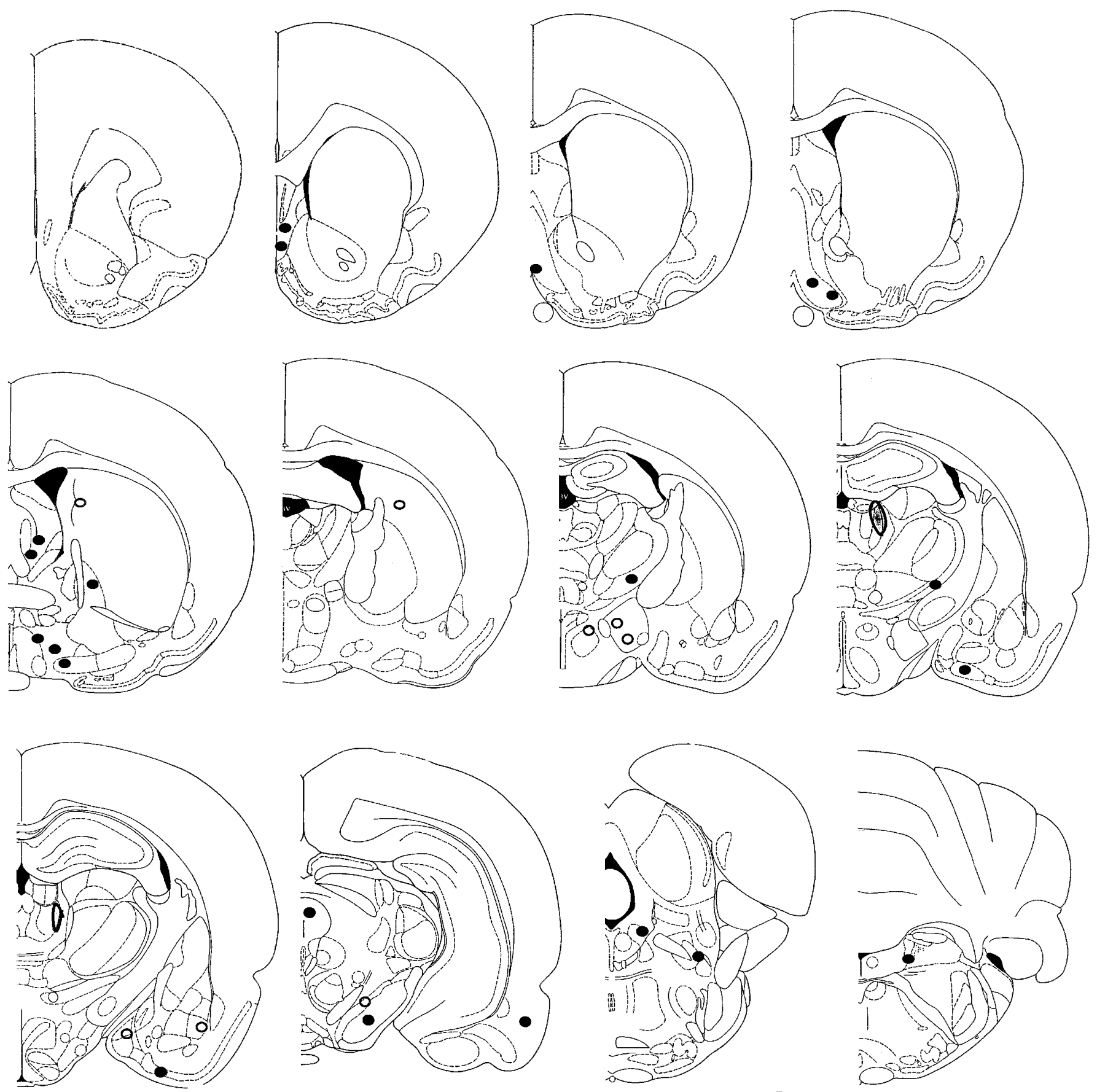

Figure 10. Structures infected after a viral injection restricted to the 1-MD. The injection site of this representative case is shown as a hatched area; solid circles represent the distribution of first-order projection neurons; open circles show the location of second-order projection neurons.

infected by preferential uptake of virions at axon terminals at the site of intracerebral injection. Indeed, previous in vitro studies (Vahlne et al., 1978, 1980; Marchand and Schwab, 1986) demonstrated that PRV and HSV have a higher affinity for axon terminals than perikarya. After uptake, virions are transported by retrograde mechanisms to the soma of the cells of origin of those afferent fibers (Card et al., 1990, 1993; Strack and Loewy, 1990). This results in infection of those cells, with an eventual transynaptic infection of second-order projection neurons (Card et al., 1995). In time, first-order infected neurons often become associated with PRV-immunoreactive astrocytes. Nevertheless, the pat- terns of infected neurons observed in this and in other studies using PRV-Bartha were consistent with transynaptic passage of virus rather than lytic spread through the extracellular space. Systematic temporal analysis has shown that replication and transynaptic passage of PRV-Bartha occurs before the development of any pathological changes in infected neurons or the appearance of viral antigen in astrocytes (Rinaman et al., 1993). Furthermore, the appearance of viral antigen in astrocytes late in the course of infection appears to reflect a protective response of the CNS aimed at isolating the infected neurons. Most importantly, it has been shown that astrocytes harbor a replication defect that pre- 

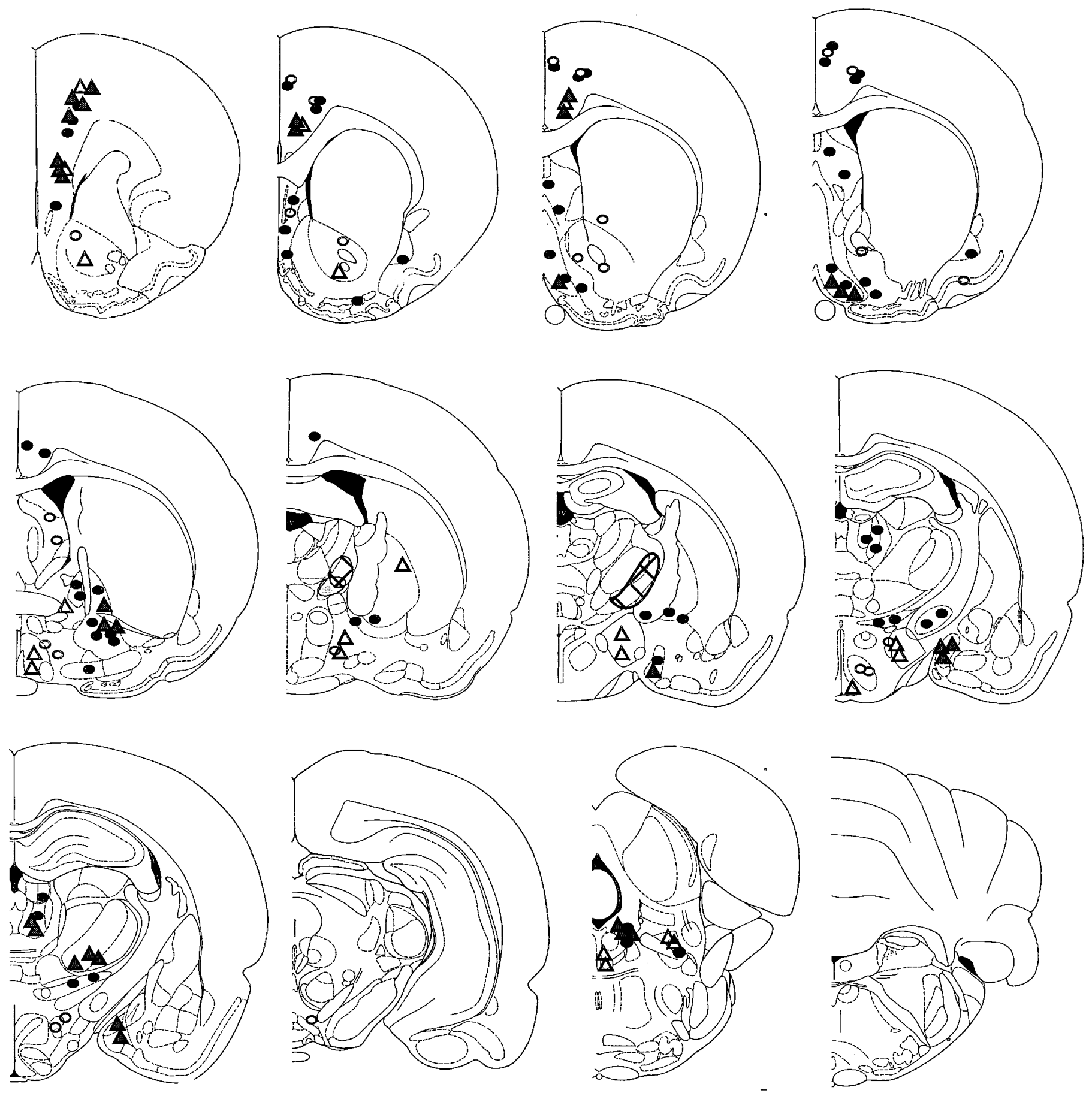

Figure 11. Injections of virus in the rostral RTN resulted in a specific pattern of infection. Circles and triangles represent first-order infected neurons (solid) and second-order infected neurons (open) for two selected cases. The distribution of infected neurons after the small injection ( gray) is shown with triangles, whereas the location of infected cells after the larger injection (hatched) is shown with circles.

vents them from producing infectious progeny (Card et al., 1993). Consequently, the appearance of immunoreactive astrocytes in relation to infected neurons provides a means of determining which populations of neurons have been replicating virus for the longest period of time and, thereby, to assess the rank order of viral transport through a multisynaptic pathway.

The reliability of the labeling observed with these viral injections is remarkable. We compared our findings with the large body of literature using conventional retrograde and anterograde tracers in these regions. With a few exceptions, our findings involving direct, first-order projections are consistent with those reported previously (Mogenson, 1987; Ray and Price, 1992). It is worth noting, however, that some regions reported as projecting to the MD were not labeled in this study. A region repeatedly proposed to project to the m-MD is the basolateral nucleus of the amygdala (BLA) (Krettek and Price, 1974, 1977; Siegel et al., 1977; Kuroda and Price, 1991; McDonald, 1992; Ray and Price, 1992). The absence of labeling in the BLA after m-MD injections 

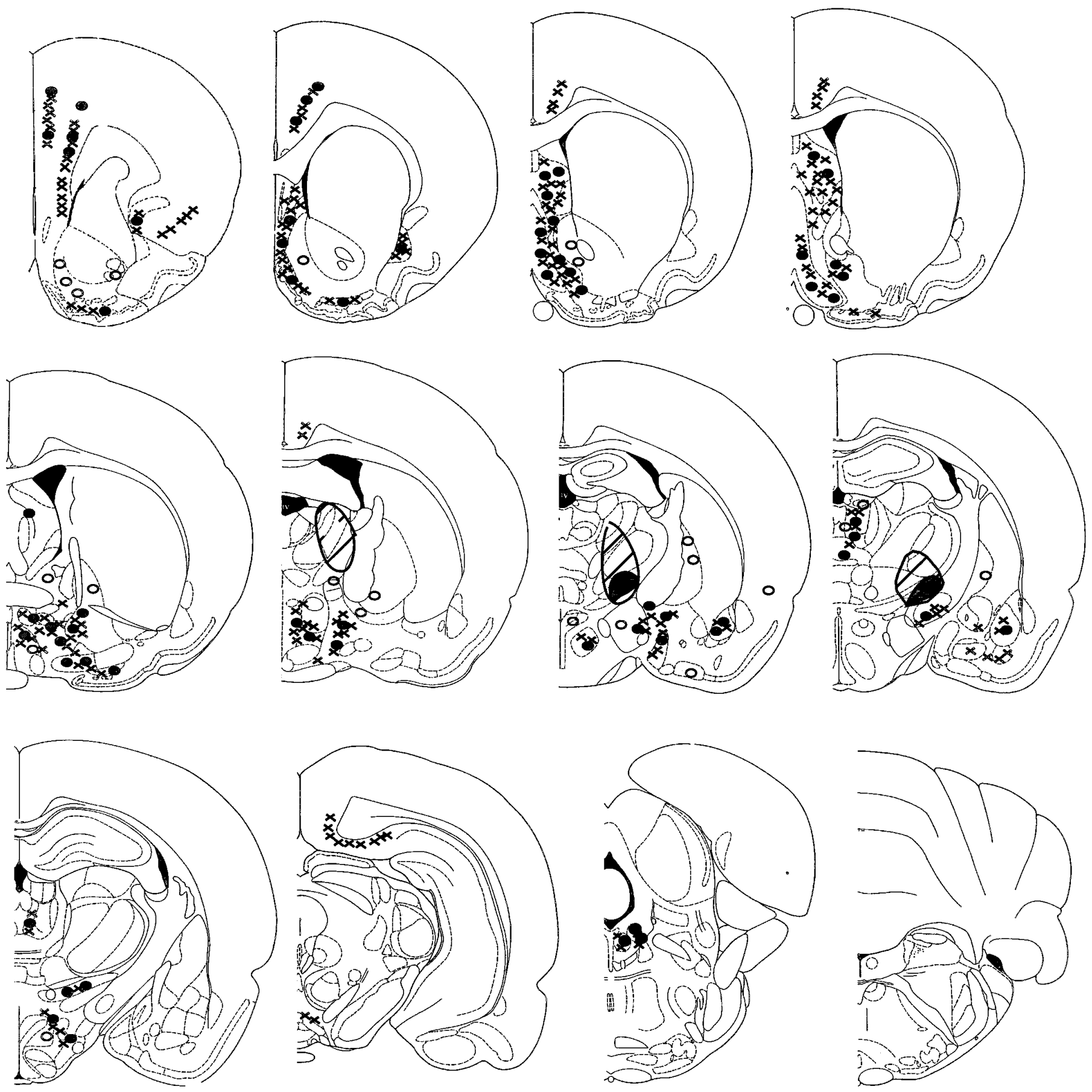

Figure 12. Co-injection of PRV and CT in the intermediate RTN results in similar first-order projections. Circles represent PRV-infected neurons (solid, first order; open, second order). Small $\times$ symbols represent the distribution of CT-labeled neurons. The extension of PRV infection in the injection site is shown as a dark area, and the larger extension of CT around the injection site is shown as a hatched area.

in this study may be the result of amygdaloid neurons being refractory to viral infection. Indeed, refractoriness of certain cell groups to PRV infection has been demonstrated previously (Card et al., 1991; Standish et al., 1995). An alternative explanation for our negative finding may be related to a recently identified characteristic of viral uptake by afferents. It has been shown recently that viral concentration and the density of innervation influences the onset of viral replication (Park et al., 1996). Because BLA projections reported previously do not appear to be numerous, it is possible that they did not accumulate sufficient virus to initiate a productive infection. We were also unable to detect labeled infected neurons in the PL PFC after PRV injections in the m-MD. Injection of the anterograde tracer PHA-L in the PL cortex has shown labeling in the m-MD (Sesack et al., 1989; Groenewegen et al., 1990; Hurley et al., 1991; Ray and Price, 1992), and similar findings were obtained with WGA-HRP (Kuroda and Price, 1991). Others have found anterograde labeling of axons in the 1-MD (but not m-MD) after tracer injection in the PL PFC (Beckstead, 1979), but we also failed to detect infected neurons in the PL PFC after 1-MD injections. Although it is 

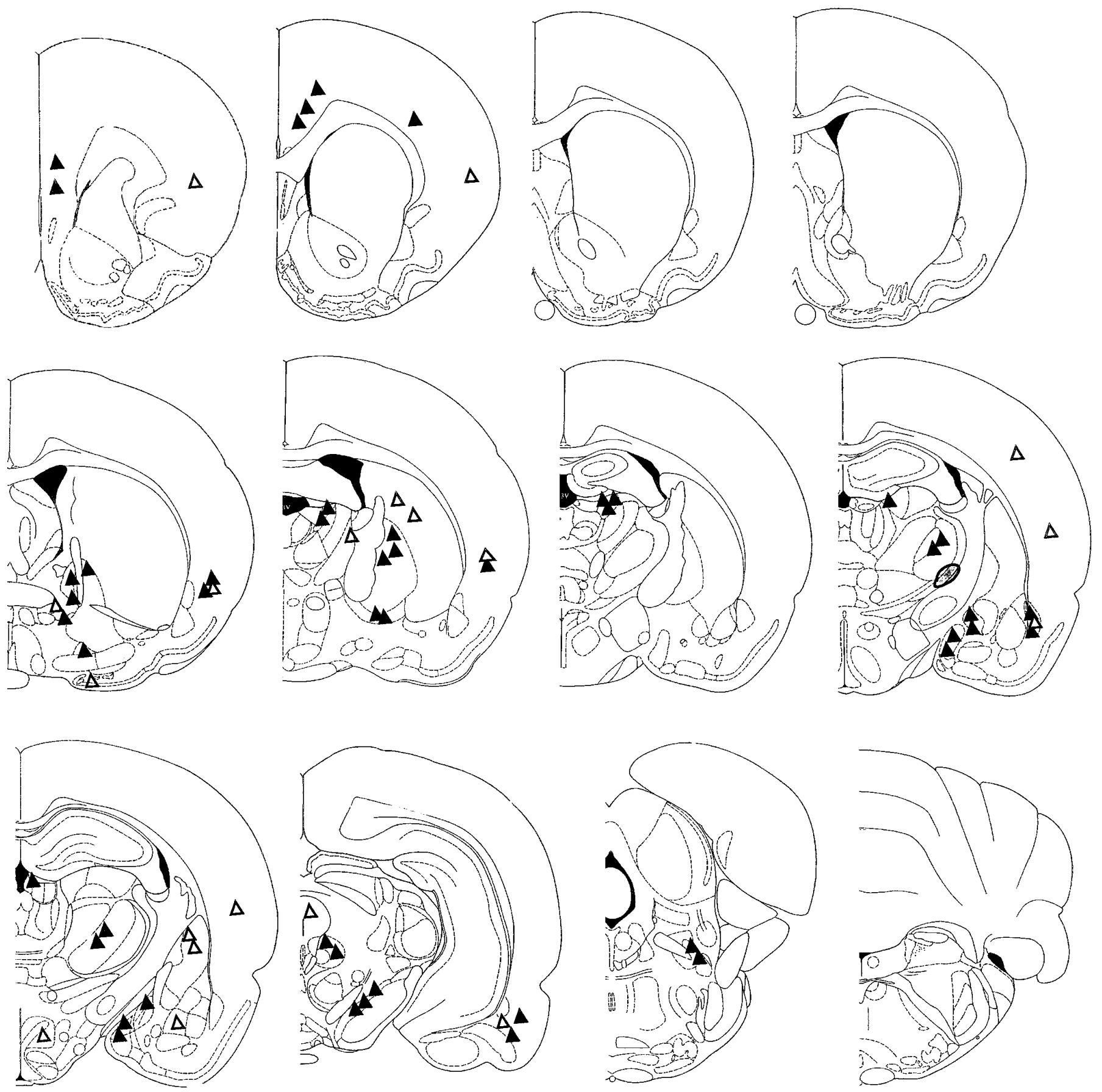

Figure 13. Distribution of infected neurons in a case representative of injections in the caudal RTN. The injection site is shown as a hatched area; solid triangles represent the distribution of first-order projection neurons, and open triangles show the distribution of second-order projection neurons.

possible that PL-MD projections may indeed be refractory to viral infection in our experimental conditions, we have observed infected neurons in the PL after injections that included the c-MD. Furthermore, these injections resulted in labeling of CT immunoreactive neurons in the PL. Therefore, it is possible that the c-MD, but not m-MD or l-MD, receives input from the PL PFC.

\section{Organization of connections between the accumbens} and MD

Injections of virus into subdivisions of the MD and RTN revealed distinct patterns of infection, suggesting the presence of parallel circuits between the basal forebrain and thalamus. First, multisynaptic projections arising in the accumbens shell relay via the medial VP and terminate selectively within the m-MD. The retrograde infection of neurons in the ventromedial part of the rostral VP after PRV injection in the m-MD is consistent with what has been reported by several groups using conventional tracers (Young et al., 1984; Haber et al., 1985; Mogenson et al., 1987; Groenewegen et al., 1990, 1993; Kuroda and Price, 1991; Ray and Price, 1992), as is the heavy labeling observed in the NDBB (Young et al., 1984; Woolf and Butcher, 1986; Hallanger et al., 1987; Mogenson et al., 1987; Groenewegen, 


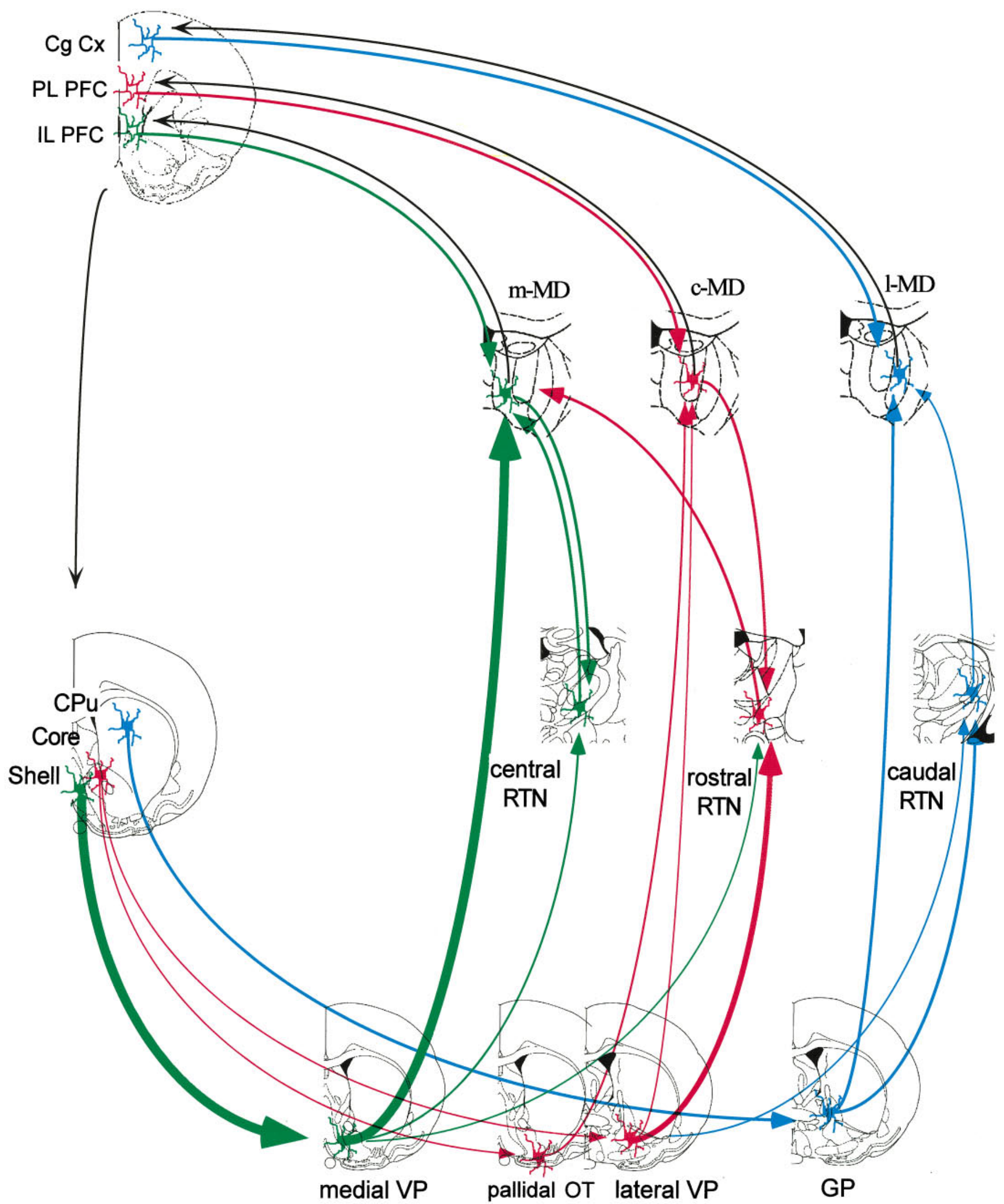

Figure 14. Parallel circuits linking the $\mathrm{CPu}$, accumbens core, and accumbens shell with pallidal and thalamocortical systems. The arrows summarize the most consistent data obtained after PRV injections into the MD or RTN regions. Green arrows represent circuitry involving the accumbens shell and medial VP, red arrows show circuits involving the accumbens core and lateral VP/pallidal OT, and blue arrows represent circuits originated from the CPu and GP. Gray arrows show cortico-thalamic and cortico-striatal projections not assessed in this study. The m-MD receives (Figure legend continues) 
1988; Ray and Price, 1990, 1992) and rostral RTN (Siegel et al., 1977; Gerfen et al., 1982; Price and Slotnick, 1983; Young et al., 1984; Woolf and Butcher, 1986; Groenewegen, 1988; Kuroda and Price, 1991; Ray and Price, 1992). Moreover, the only striatal region infected after m-MD injections was the accumbens shell in the cases with more advanced infection. The following findings in this study strongly support the conclusion that the VP serves as a relay station for shell projections to the m-MD: (1) m-MD injections resulted in more advanced signs of infection in VP neurons than in the shell; (2) labeling in the shell was consistently detected in the cases with more advanced signs of infection, whereas it was minimal or absent in animals killed earlier in the course of the infection; and (3) infected cells could not be observed in the shell after $\mathrm{m}-\mathrm{MD}$ viral injections in the VP-lesioned animal. Thus, the most likely route of infection in the shell is via the medial VP; this is consistent with reports of accumbens shell neurons projecting to the ventromedial aspect of the VP (Zahm and Heimer, 1990; Záborszky and Cullinan, 1992; Napier et al., 1995). In addition, a shell medial VP/m-MD-axis has recently been proposed in a study combining conventional tracers in the $\mathrm{VP}$ and MD (Zahm et al., 1996).

A second circuit involves projections from the accumbens core to the lateral VP and the pallidal region of the OT, then to the c-MD and rostral RTN. Injections that included the c-MD resulted in first-order infection of neurons in the polymorph (pallidal) region of the OT and in the caudal and lateral subcommissural region of the VP and in second-order infection of neurons in the core and striatal OT. It should be noted that in all these cases, the injections also extended into the neighboring m-MD or l-MD, and the pallidal and striatal infection patterns were a combination of those typical of $\mathrm{m}-\mathrm{MD}$ and 1-MD injections with the lateral VP and accumbens core. This projection arising from the core should be taken with caution, because in all cases, the number of cells infected in the core was very sparse. It is possible that the primary thalamic target of coreoriginated projections was missed in this study. Indeed, it has been proposed that neurons in the laterodorsal VP receiving input from the core project to the caudal and ventral parts of the m-MD (Groenewegen et al., 1990). We consistently found second-order infected cells in the accumbens core in every case in which the c-MD was included in the injection site. This argues for a core-lateral VP-c-MD pathway. However, it has been demonstrated recently that the accumbens-VP projections to the MD arise disproportionately from the shell compared with those originating in the core (Zahm et al., 1996). Thus, it is possible that the primary core output is directed to regions other than the MD. Indeed, a subset of core neurons has been reported to preferentially project to the substantia nigra pars reticulata (Montaron et al., 1996).

A third circuit shown by our data involves projections from the $\mathrm{CPu}$ to the GP to the l-MD. Injections in the l-MD resulted in a pattern of retrograde labeling consistent with that reported previously (Haber et al., 1985; Groenewegen, 1988; Ray and Price, 1992). First-order projection neurons were observed in the GP, and second-order neurons were detected in the $\mathrm{CPu}$. With the exception of the two cases with survival times well beyond the others, first-order projection cells were not observed in the VP. This is consistent with classical tracer studies showing that the
l-MD does not receive input from the VP (Ray and Price, 1992; Groenewegen et al., 1993).

\section{Organization of connections between accumbens and RTN}

Different regions within the RTN were also targets of striatal and accumbal projections via the GP and VP. Injections into the ventral part of the rostral RTN resulted in an extensive infection of VP neurons and in second-order infection in the nucleus accumbens core and shell. In the animals injected in more dorsal and caudal regions of the rostral RTN, infected cells were detected in the VP, and second-order neurons were observed in the accumbens shell and not in the core. This suggests that the shell, in addition to its projection to the m-MD via the VP, may also target a discrete region within the RTN, whereas the core, in addition to targeting the c-MD via the VP, also projects to a different RTN region. The absence of this pattern of infection in cases in which the injection was close to, but did not involve, the RTN supports this conclusion.

PRV injections into the caudal RTN resulted in infection of cells in the GP that had the characteristic labeling pattern of first-order projection cells. In addition, second-order projection neurons were labeled in the $\mathrm{CPu}$ but were absent in the accumbens. These findings are consistent with results from injections of anterograde tracers in the GP that yielded labeling of terminals in the caudal RTN (Gandia et al., 1993; Philipson et al., 1993) and suggest that the so-called "indirect pathway" of striatal circuits may have a target in the RTN, as proposed by Parent and colleagues in monkeys (Hazrati and Parent, 1991; Parent and Hazrati, 1995). This pathway includes projections from the $\mathrm{CPu}$ to the GP (or GPe in primates), which in turn projects to the entopeduncular nucleus (GPi in primates), providing an input to thalamocortical projections that are distinct from the "direct pathway." In this case, a GP-RTN projection may serve as a means to further control the flow of information in the basal ganglia circuits that may be particularly relevant to the integration of limbic, motor, and sensory systems. Indeed, the RTN injection that resulted in GP labeling also labeled first-order projection cells in the ventral anterior-VL thalamic nuclei. Because RTNventral thalamic connections are known to be reciprocal (Cornwall et al., 1990), it is possible that GP input to the caudal RTN may be conveyed to the ventrolateral nucleus of the thalamus. This thalamic region is also a target of projections originating in the CPu via the "direct pathway" (Alexander and Crutcher, 1990).

\section{Parallel circuits involving the MD and RTN}

The results presented here reveal a substantial degree of segregation in the projections from the accumbens core and shell regions to the thalamus. Indeed, while efferents from the shell region of the accumbens, via its projections to the medial VP, contact the m-MD and rostral-intermediate regions of the RTN, the projections from the core region, via the lateral VP, affect primarily the c-MD and rostral pole of the RTN. In addition, $\mathrm{CPu}$ efferents target the 1-MD and a caudal region of the RTN via the GP. These parallel circuits revealed by the transynaptic passage of

\section{$\leftarrow$}

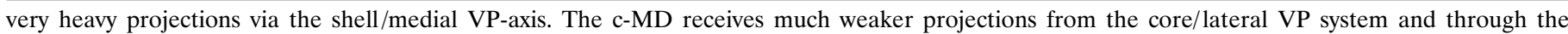

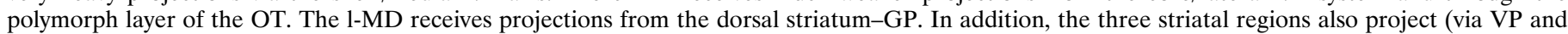

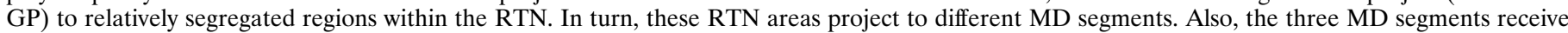

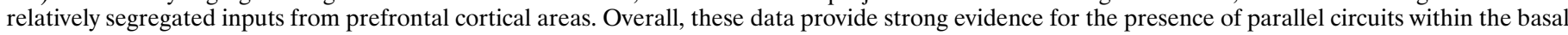
ganglia-thalamic projections, which are not completely closed, allowing for interactions among them. 
this neurotropic virus are a confirmation of what has been proposed by the analysis of separate conventional tracer studies (Groenewegen et al., 1990, 1993; Zahm et al., 1996), with the shell-medial VP/m-MD-axis being the strongest in our dataset (Fig. 14 ).

As suggested by in vivo intracellular recordings in the RTN (Lavín and Grace, 1994), we have provided additional anatomical evidence for parallel VP-RTN projections. Furthermore, the RTN and MD regions studied appear to project to each other. Discrete RTN regions receiving inputs from discrete MD areas in turn send projection to restricted areas within the MD that are not necessarily the same as those projecting to these RTN regions. Nonetheless, the shell, core, and $\mathrm{CPu}$-originated circuits remain segregated within both the MD and RTN. These findings are consistent with previous studies using anterograde tracers injected in the rostral pole of the RTN that labeled terminals within the c-MD (Philipson et al., 1993), as well as with the ability of HRP injections in the MD to retrogradely label cells in the rostral pole of the RTN (Tai et al., 1995).

Even though core and shell neurons project to different thalamic target areas, there are some interactions between these parallel circuits (Fig. 14). The MD itself is not likely to be a site for interactions between these parallel circuits, because dendritic trees of cells located in the different segments of the MD were found to be confined to each MD subdivision (Kuroda et al., 1992). Furthermore, there was no evidence for local connections between MD subdivisions in our analysis; i.e., injections of PRV in one segment did not lead to retrograde infection of MD neurons in other MD segments, nor did the analysis of CT transport provide evidence of such connection. However, the shell medial $\mathrm{VP} / \mathrm{m}$-MD-axis could be affected by core output by virtue of the core-receiving region of the RTN (rostral pole) projections to the m-MD. Furthermore, these circuits may also be interconnected at the level of thalamocortical projections. The m-MD is known to project to both PL and IL PFC, the former of which projects to the accumbens core. These results support the idea of these parallel circuits being "open interconnected" instead of segregated (Joel and Weiner, 1994), although the closed or open nature of the cortical components of these loops remains to be explored.

\section{Functional implications}

The MD regions targeted by the striatal regions have been demonstrated to be the origin of projections to cortical regions that in turn project back to the accumbens and striatum. Thus, the m-MD projects to the PL and IL PFC, the c-MD to the lateral orbital and ventral agranular insular cortex, and the l-MD to the anterior cingulate cortex (Leonard, 1972; Siegel et al., 1977; Sesack et al., 1989; Kuroda and Price, 1991; Ray and Price, 1992; Groenewegen and Berendse, 1994; Condé et al., 1995). The involvement of the RTN in these circuits may provide the bases for a control of MD-cortical activity. Indeed, it is known that the RTN controls thalamocortical activity by modulating the oscillatory activity of thalamic cells (Steriade et al., 1994). Because different regions within the RTN control discrete thalamic regions (Mitrofanis and Guillery, 1993), it is possible that the RTN areas identified in these experiments selectively control the MD-PFC activity. Thus, the RTN region that receives inputs from the striatopallidal system appears to control the activity of the thalamocortical regions that are targeted by the same component of the striatopallidal system. Such an arrangement bears a striking similitude to that of cortical inputs on RTN-thalamic nuclei interactions in that the pallidal regions send projections to mutually interconnected
RTN/MD areas. In this way, the VP and GP exert a tight control over RTN-MD interactions similar to that of cortical input. However, pallidal input to the thalamus is known to be GABAergic (Young et al., 1984). Although highly speculative, it is possible that these pallidal regions are involved in rhythm generation within the thalamocortical system. This is particularly attractive, because most accumbens neurons and many VP neurons recorded in vivo exhibit a bistable pattern of activity, alternating between active and silent states at $\sim 1 \mathrm{~Hz}$ (O'Donnell and Grace, 1995b; Lavín and Grace, 1996), which is precisely the frequency at which many RTN units oscillate (Steriade et al., 1993a; Lavín and Grace, 1994). Although it may be possible that this $1 \mathrm{~Hz}$ RTN activity reflects basal ganglia input via the striatopallidal system, it is also possible that basal ganglia oscillatory activity is the result of RTN-dependent cortical activity.

The RTN is known to exert a control on the oscillatory activity of thalamocortical projections (Steriade et al., 1993a), including those that appear to be involved in wakefulness or selective attention (Steriade et al., 1993b). Therefore, the activity of accumbens-RTN projections may have an impact on functions such as general attentiveness or a broadening of attentional focus via its modulation of overall thalamocortical activity (Lavín and Grace, 1994). It has been suggested that the RTN comprises "topographic maps" representing different cortical areas (Mitrofanis and Guillery, 1993), and our data are consistent with this view. In this way, the RTN may be capable of selectively activating specific thalamocortical circuits to allow a focusing of attention toward a specific stimulus or cognitive state, with limbic inputs originating in the accumbens directing the orientation of such activation based on the affective associations generated by the stimulus. This takes place, as shown by Steriade et al. (1988), by RTN and thalamic relay cells switching their firing pattern in the waking process from rhythmic bursts to single spike activity. Although these changes have been discussed primarily with respect to the role of sensory inputs and attention, the results presented here, when combined with our previous electrophysiological data (Lavín and Grace, 1994), suggest a role for limbic regions in modulating such activity changes. In this way, striatopallidal activity may ultimately adjust the level of rhythmicity within the RTN-MD system by acting on RTN neuron dendrites, which have been proposed to "tune" RTN response to cortical inputs (Destexhe et al., 1996). Furthermore, the RTN has been proposed to synchronize the $40 \mathrm{~Hz}$ thalamocortical activity (Paré and Llinás, 1995). The connections reported here may represent the means by which the limbic striatum (i.e., the nucleus accumbens) has an influence on the activity of systems proposed to have a role in consciousness. A computational analogy for these interactions would be that setting a particular level of RTN activity (and therefore of control of thalamocortical function) is like loading the appropriate drivers for the activation of the cortical regions required at a given moment. Basal ganglia input, via GP and VP, may change the status of RTN drivers for PFC activation. In this way, our analysis by viral tracing techniques provides an anatomical basis for the proposed involvement of the nucleus accumbens in attentional mechanisms (Reading et al., 1991; Joseph et al., 1992; Lavín and Grace, 1994) and for the attentional disturbances that have been observed in schizophrenics (Goldberg et al., 1993). Indeed, a malfunction of the basal ganglia may eventually result in the loading of inappropriate RTN-MD drivers in the schizophrenic brain, resulting in improper cortical activation. Such a disturbance may also be reflected in the reported 
coincidence between slow-wave sleep deficit and negative symptoms in schizophrenia (Keshavan et al., 1995).

In summary, our data show that multisynaptic circuits from the $\mathrm{CPu}$ and accumbens core and shell to the MD and reticular thalamic nuclei via the VP are organized in a series of parallel loops that nonetheless exhibit some interactions. The accumbens shell is the primary source of transynaptic striatal input to the MD, whereas the sparse accumbens core transynaptic projections to the thalamus appear to be primarily directed to the RTN.

\section{REFERENCES}

Alexander GE, Crutcher MD (1990) Functional architecture of basal ganglia circuits: neural substrates of parallel processing. Trends Neurosci 13:266-271.

Aylward RLM, Totterdell S (1993) Neurons in the ventral subiculum, amygdala and entorhinal cortex project to the nucleus accumbens: their input from somatostatin-immunoreactive boutons. J Chem Neuroanat $6: 31-42$.

Bartha A (1961) Experimental reduction of virulence of Aujeszky's disease virus. Magy Allatorv Lapja 16:43-45.

Beckstead RM (1979) An autoradiographic examination of corticostriatal and subcortical projections of the mediodorsal-projection (prefrontal) cortex in the rat. J Comp Neurol 184:43-62.

Berendse HW, Groenewegen HJ (1990) Organization of the thalamostriatal projections in the rat, with special emphasis on the ventral striatum. J Comp Neurol 299:187-228.

Berendse HW, Galis-de Graaf Y, Groenewegen HJ (1992) Topographical organization and relationship with ventral striatal compartments of prefrontal corticostriatal projections in the rat. J Comp Neurol 316:314-347.

Braun AR, Stoetter B, Randolph C, Hsiao JK, Vladar K, Gernert J, Carson RE, Herscovitch P, Chase TN (1993) The functional neuroanatomy of Tourette's syndrome: an FDG-PET study. I. Regional changes in cerebral glucose metabolism differentiating patients and controls. Neuropsychopharmacology 9:277-291.

Brog JS, Salyapongse A, Deutch AY, Zahm DS (1993) The patterns of afferent innervation of the core and shell in the "accumbens" part of the rat ventral striatum: immunohistochemical detection of retrogradely transported fluoro-gold. J Comp Neurol 338:255-278.

Card JP, Enquist LW (1994) Use of pseudorabies virus for definition of synaptically linked populations of neurons. In: Methods in molecular genetics (Adolph KW, ed), pp 363-382. New York: Academic.

Card JP, Enquist LW (1995) Neurovirulence of pseudorabies virus. Crit Rev Neurobiol 9:137-162.

Card JP, Rinaman L, Schwaber JS, Miselis RR, Whealy ME, Robbins AK, Enquist LW (1990) Neurotropic properties of pseudorabies virus: uptake and transneuronal passage in the rat central nervous system. J Neurosci 10:1974-1994.

Card JP, Whealy ME, Robbins AK, Moore RY, Enquist LW (1991) Two $\alpha$-herpesvirus strains are transported differentially in the rodent visual system. Neuron 6:957-969.

Card JP, Whealy ME, Robbins AK, Enquist LW (1992) Pseudorabies virus envelope glycoprotein gI influences both neurotropism and virulence during infection of the rat visual system. J Virol 66:3032-3041.

Card JP, Rinaman L, Lynn RB, Lee B-H, Meade RP, Miselis RR, Enquist LW (1993) Pseudorabies virus infection of the rat central nervous system: ultrastructural characterization of viral replication, transport, and pathogenesis. J Neurosci 13:2515-2539.

Card JP, Dubin JR, Whealy ME, Enquist LW (1995) Influence of infectious dose upon productive replication and transynaptic passage of pseudorabies virus in rat central nervous system. J Neurovirol 1:349-358.

Comings DE (1987) A controlled study of Tourette syndrome. VII. Summary: a common genetic disorder causing disinhibition of the limbic system. Am J Hum Genet 41:839-866.

Condé F, Maire-Lepoivre E, Audinat E, Crépel F (1995) Afferent connections of the medial frontal cortex of the rat. II. Cortical and subcortical afferents. J Comp Neurol 352:567-593.

Cornwall J, Cooper JD, Phillipson OT (1990) Projections to the rostral reticular thalamic nucleus in the rat. Exp Brain Res 80:157-171.

Csernansky JG, Murphy GM, Faustman WO (1991) Limbic/mesolimbic connections and the pathogenesis of schizophrenia. Biol Psychiatry 30:383-400.
DeFrance JF, Yoshihara H (1975) Fimbria input to accumbens septi. Brain Res 90:159-163.

DeFrance JF, Marchand JF, Sikes RW, Chronister RB, Hubbard JI (1985) Characterization of fimbria input to nucleus accumbens. J Neurophysiol 54:1553-1567.

Destexhe A, Contreras D, Steriade M, Sejnowski TJ, Huguenard JR (1996) In vivo, in vitro, and computational analysis of dendritic calcium currents in thalamic reticular neurons. J Neurosci 16:169-185.

Deutch AY, Cameron DS (1992) Pharmacological characterization of dopamine systems in the nucleus accumbens core and shell. Neuroscience 46:49-56.

Deutch AY, Lee MC, Iadarola MJ (1992) Regionally specific effects of atypical antipsychotic drugs on striatal fos expression: the nucleus accumbens shell as a locus of antipsychotic action. Mol Cell Neurosci 3:332-341.

Enquist LW (1994) Infection of the mammalian nervous system by pseudorabies virus (PRV). Semin Virol 5:221-231.

Enquist LW, Card JP (1996) Pseudorabies virus: a tool for tracing connections. In: Protocols for gene transfer in neuroscience: towards gene therapy of neurobiological disorders (Lowenstein PR, Enquist LW, eds), pp 333-348. New York: Wiley.

Enquist LW, Levitt P, Card JP (1993) Connections of the adult prefrontal cortex revealed by intracerebral injection of a swine alpha herpesvirus. Soc Neurosci Abstr 11:589.

Fuller TA, Russchen FT, Price JL (1987) Sources of presumptive glutamatergic/aspartergic afferents to the rat ventral striatopallidal region. J Comp Neurol 258:317-338.

Gandia JA, de las Heras S, García M, Giménez Amaya JM (1993) Afferent projections to the reticular thalamic nucleus from the globus pallidus and the substantia nigra in the rat. Brain Res Bull 32:351-358.

Gerfen CR, Staines WA, Arbuthnott GW, Fibiger HC (1982) Crossed connections of the substantia nigra in the rat. J Comp Neurol 207:283-303.

Goldberg TE, Greenberg RD, Griffin SJ, Gold JM, Kleinman JE, Pickar D, Schulz SC, Weinberger DR (1993) The effect of clozapine on cognition and psychiatric symptoms in patients with schizophrenia. $\mathrm{Br} \mathbf{J}$ Psychiatry 162:43-48.

Grace AA (1992) The depolarization block hypothesis of neuroleptic action: implications for the etiology and treatment of schizophrenia. J Neural Transm Gen Sect 36:91-131.

Gray JA, Feldon J, Rawlins JNP, Hemsley DR, Smith AD (1991) The neuropsychology of schizophrenia. Behav Brain Sci 14:1-84.

Groenewegen HJ (1988) Organization of the afferent connections of the mediodorsal thalamic nucleus in the rat, related to the mediodorsalprefrontal topography. Neuroscience 24:379-431.

Groenewegen HJ, Berendse HW (1994) The specificity of the "nonspecific" midline and intralaminar thalamic nuclei. Trends Neurosci 17:52-57.

Groenewegen HJ, Becker NEHM, Lohman AHM (1980) Subcortical afferents of the nucleus accumbens septi in the cat, studied with retrograde axonal transport of horseradish peroxidase and bisbenzimid. Neuroscience 5:1903-1916.

Groenewegen HJ, Berendse HW, Wolters JG, Lohman AHM (1990) The anatomical relationship of the prefrontal cortex with the striatopallidal system, the thalamus and the amygdala: evidence for a parallel organization. Prog Brain Res 85:95-118.

Groenewegen HJ, Berendse HW, Meredith GE, Haber SN, Voorn P, Wolters JG, Lohman AHM (1991) Functional anatomy of the ventral, limbic system-innervated striatum. In: The mesolimbic dopamine system: from motivation to action (Willner P, Scheel-Kruger J, eds), pp 19-59. New York: Wiley.

Groenewegen HJ, Berendse HW, Haber SN (1993) Organization of the output of the ventral striatopallidal system in the rat: ventral pallidal efferents. Neuroscience 57:113-142.

Haber SN, Groenewegen HJ, Grove EA, Nauta WJH (1985) Efferent connections of the ventral pallidum: evidence of a dual striato pallidofugal pathway. J Comp Neurol 235:322-335.

Hallanger AE, Levey AI, Lee HJ, Rye DB, Wainer BH (1987) The origins of cholinergic and other subcortical afferents to the thalamus in the rat. J Comp Neurol 262:105-124.

Hazrati L-N, Parent A (1991) Projection from the external pallidum to the reticular thalamic nucleus in the squirrel monkey. Brain Res 550:142-146.

Heimer L, Wilson RD (1975) The subcortical projections of the allocortex: similarities in the neural associations of the hippocampus, the 
piriform cortex, and the neocortex. In: The Golgi centennial symposium. Perspectives in neurobiology (Santini M, ed), pp 177-193. New York: Raven.

Heimer L, Zahm DS, Churchill L, Kalivas PW, Wohltmann C (1991) Specificity in the projection patterns of accumbal core and shell in the rat. Neuroscience 41:89-125.

Hsu SM, Raine L, Fanger H (1981) Use of avidin-biotin-peroxidase techniques: a comparison between ABC and unlabeled antibody (PAP) procedures. J Histochem Cytochem 29:577-580.

Hurley KM, Herbert H, Moga MM, Saper CB (1991) Efferent projections of the infralimbic cortex of the rat. J Comp Neurol 308:249-276

Jansen ASP, Ter Horst GJ, Mettenleiter TC, Loewy AD (1992) CNS cell groups projecting to the submandibular parasympathetic preganglionic neurons in the rat: a retrograde transneuronal viral cell body labeling study. Brain Res 572:253-260.

Jansen ASP, Wessendorf MW, Loewy AD (1995) Transneuronal labeling of CNS neuropeptide and monoamine neurons after pseudorabies virus injections into the stellate ganglion. Brain Res 653:1-24.

Joel D, Weiner I (1994) The organization of the basal gangliathalamocortical circuits: open interconnected rather than closed segregated. Neuroscience 63:363-379.

Jongen-Rêlo AL, Docter GJ, Jonker AJ, Vreugdenhil E, Groenewegen HJ, Voorn P (1994a) Differential effects of dopamine depletion on the binding and mRNA levels of dopamine receptors in the shell and core of the rat nucleus accumbens. Mol Brain Res 25:333-343.

Jongen-Rêlo AL, Voorn P, Groenewegen HJ (1994b) Immunohistochemical characterization of the shell and core territories of the nucleus accumbens in the rat. Eur J Neurosci 6:1255-1264.

Joseph MH, Young AMJ, Gray JA (1992) Reinforcement, conditioning and dopamine function in the nucleus accumbens. In: Monitoring molecules in neuroscience (Rollema EH, Westerink BHC, Drifjhout WJ, eds), pp 200-203. Groningen, The Netherlands: University Centre for Pharmacy.

Kalivas PW, Duffy P (1995) Selective activation of dopamine transmission in the shell of the nucleus accumbens by stress. Brain Res 675:325-328.

Kelley AE, Domesick VB (1982) The distribution of the projection from the hippocampal formation to the nucleus accumbens in the rat: an anterograde- and retrograde-horseradish peroxidase study. Neuroscience 7:2321-2335.

Keshavan MS, Miewald J, Haas G, Sweeney J, Ganguli R, Reynolds CF (1995) Slow-wave sleep and symptomatology in schizophrenia and related psychotic disorders. J Psychiatry Res 29:303-314.

Krettek JE, Price JL (1974) A direct input from the amygdala to the thalamus and the cerebral cortex. Brain Res 67:169-174.

Krettek JE, Price JL (1977) Projections from the amygdaloid complex to the cerebral cortex and thalamus in the rat and cat. J Comp Neurol 172:687-722.

Kuroda M, Price JL (1991) Synaptic organization of projections from the basal forebrain structures to the mediodorsal thalamic nucleus of the rat. J Comp Neurol 303:513-533.

Kuroda M, López-Mascaraque L, Price JL (1992) Neuronal and synaptic composition of the mediodorsal thalamic nucleus in the rat: a light and electron microscopic Golgi study. J Comp Neurol 326:61-81.

Lavín A, Grace AA (1994) The modulation of mediodorsal and dorsal thalamic nuclei by the ventral pallidum: its role in the regulation of thalamocortical activity in the basal ganglia. Synapse 18:104-127.

Lavín A, Grace AA (1996) Physiological properties of rat ventral pallidal neurons recorded intracellularly in vivo. J Neurophysiology 75 : 1432-1443.

Leak RK, Card JP, Moore RY (1995) Application of the pseudorabies virus (PRV) to tracing functional pathways in the brain. Soc Neurosci Abstr 21:178.

Leonard CM (1972) The connections of the dorsomedial nuclei. Brain Behav Evol 6:524-541.

Loewy AD (1995) Pseudorabies virus: a transneuronal tracer for neuroanatomical studies: In: Viral vectors. Gene therapy and neuroscience applications (Kaplitt MG, Loewy AD, eds), pp 349-366. San Diego: Academic.

Marchand CF, Schwab M (1986) Binding, uptake and retrograde axonal transport of herpes virus in sympathetic neurons. Brain Res 383:262-270.

Matthysse S (1981) Nucleus accumbens and schizophrenia, 1980. In: The neurobiology of the nucleus accumbens (Chronister RB, DeFrance JF, eds), pp 351-359. Brunswick, ME: Hauer Institute.
McDonald AJ (1991) Organization of amygdaloid projections to the prefrontal cortex and associated striatum in the rat. Neuroscience 44:1-14.

McDonald AJ (1992) Projection neurons of the basolateral amygdala: a correlative Golgi and retrograde tract tracing study. Brain Res Bull 28:179-185.

McLean IW, Nakane PK (1974) Periodate-lysine-paraformaldehyde fixative for immunoelectron microscopy. J Histochem Cytochem 22:1077-1083.

Meredith GE, Blank B, Groenewegen HJ (1989) The distribution and compartmental organization of the cholinergic neurons in nucleus accumbens of the rat. Neuroscience 31:327-345.

Meredith GE, Agolia R, Arts MPM, Groenewegen HJ, Zahm DS (1992) Morphological differences between projection neurons of the core and shell in the nucleus accumbens of the rat. Neuroscience 50:149-162.

Meredith GE, Ingham CA, Voorn P, Arbuthnott GW (1993) Ultrastructural characteristics in enkephalin-immunoreactive boutons and their postsynaptic targets in the shell and core of the nucleus accumbens of the rat. J Comp Neurol 332:224-236.

Meredith GE, Pattiselano A, Groenewegen HJ, Haber SN (1996) Shell and core in monkey and human nucleus accumbens identified with antibodies to calbindin- $\mathrm{D}_{28 \mathrm{k}}$. J Comp Neurol 365:628-639.

Mettenliziter TC (1995) Molecular properties of alphaherpesviruses used in transneuronal pathway tracing. In: Viral vectors. Gene therapy and neuroscience applications (Kaplitt MG, Loewy AD, eds), pp 367393. San Diego: Academic.

Middleton FA, Strick PL (1994) Anatomical evidence for cerebellar and basal ganglia involvement in higher cognitive function. Science 266:458-461.

Mitrofanis J, Guillery RW (1993) New views of the thalamic reticular nucleus in the adult and developing brain. Trends Neurosci 16:240-245.

Moga M, Weis RP, Moore RY (1995) Efferent projections of the paraventricular thalamic nucleus in the rat. J Comp Neurol 359:221-238.

Mogenson GJ (1987) Limbic-motor interaction. Prog Psychobiol Physiol Psychol 12:117-170.

Mogenson GJ, Jones DL, Yim CY (1980) From motivation to action: functional interface between limbic system and the motor system. Prog Neurobiol 14:69-97.

Mogenson GJ, Swanson LW, Wu M (1983) Neural projections from nucleus accumbens to globus pallidus, substantia innominata, and lateral preoptic-lateral hypothalamic area: an anatomical and electrophysiological investigation in the rat. J Neurosci 3:189-201.

Mogenson GJ, Ciriello J, Garland J, Wu M (1987) Ventral pallidum projections to mediodorsal nucleus of the thalamus: an anatomical and electrophysiological investigation in the rat. Brain Res 404:221-230.

Montaron MF, Deniau JM, Menetrey A, Glowinski J, Thierry AM (1996) Prefrontal cortex inputs of the nucleus accumbens-nigro-thalamic circuit. Neuroscience 71:371-382.

Moore RY, Speh JC, Card JP (1995) The retinohypothalamic tract originates from a distinct subset of retinal ganglion cells. J Comp Neurol 352:351-366.

Nadelhaft I, Vera PL, Card JP, Miselis RR (1992) Central nervous system neurons labeled following the injection of pseudorabies virus into the rat urinary bladder. Neurosci Lett 143:271-274.

Napier TC, Mitrovic I, Churchill L, Klitenick MA, Lu X-Y, Kalivas PW (1995) Substance $P$ in the ventral pallidum: projection from the ventral striatum, and electrophysiological and behavioral consequences of pallidal substance P. Neuroscience 69:59-70.

O'Donnell P, Grace AA (1993a) Dopaminergic modulation of dye coupling between neurons in the core and shell regions of the nucleus accumbens. J Neurosci 13:3456-3471.

O'Donnell P, Grace AA (1993b) Physiological and morphological properties of accumbens core and shell neurons recorded in vitro. Synapse 13:135-160.

O'Donnell P, Grace AA (1995a) Different effects of subchronic clozapine and haloperidol on dye coupling between neurons in the rat striatal complex. Neuroscience 66:763-767.

O'Donnell P, Grace AA (1995b) Synaptic interactions among excitatory afferents to nucleus accumbens neurons: hippocampal gating of prefrontal cortical input. J Neurosci 15:3622-3639.

O’Donnell P, Lavín A, Grace AA, Card JP (1995) Segregated ventral pallidum-thalamic projections from the core and shell regions of the rat nucleus accumbens: transynaptic retrograde labeling using pseudorabies virus. Soc Neurosci Abstr 21:1188.

Onn SP, Grace AA (1995) Repeated treatment with haloperidol and 
clozapine exerts differential effects on dye coupling between neurons in subregions of the striatum and accumbens. J Neurosci 15:7024-7036.

Paré D, Llinás R (1995) Conscious and pre-conscious processes as seen from the standpoint of sleep-waking cycle neurophysiology. Neuropsychologia 33:1155-1168.

Parent A, Hazrati L-N (1995) Functional anatomy of the basal ganglia. I. The cortico-basal ganglia-thalamo-cortical loop. Brain Res Rev 20:91-127.

Park J, Enquist LW, Moore RY, Card JP (1996) The effect of viral concentration upon invasiveness, replication, and transynaptic passage of pseudorabies virus injected into striatum. Soc Neurosci Abstr 22:1730.

Paxinos G, Watson C (1986) The rat brain in stereotaxic coordinates. Sydney: Academic.

Pennartz CMA, Dolleman-van der Weel MJ, Lopes da Silva FH (1992) Differential membrane properties and dopamine effects in the shell and core of the rat nucleus accumbens studied in vitro. Neurosci Lett 136:109-112.

Philipson OT, Cornwall J, Jones MW, Kilpatrick IC (1993) Thalamic control of dopamine function: a role for the reticular nucleus. Biogen Amines 9:395-402.

Price JL, Slotnick BM (1983) Dual olfactory representation in the rat thalamus: an anatomical and electrophysiological study. J Comp Neurol 215:63-77.

Ray JP, Price JL (1990) Postnatal changes in the density and distribution of neurotensin-like immunoreactive fibers in the mediodorsal nucleus of the thalamus in the rat. J Comp Neurol 292:269-282.

Ray JP, Price JL (1992) The organization of the thalamocortical connections of the mediodorsal thalamic nucleus in the rat, related to the ventral forebrain-prefrontal cortex topography. J Comp Neurol 323:167-197.

Reading PJ, Dunnett SB, Robbins TW (1991) Dissociable roles of the ventral, medial and lateral striatum on the acquisition and performance of a complex visual stimulus-response habit. Behav Brain Res 45:147-161.

Rinaman L, Card JP, Enquist LW (1993) Spatiotemporal responses of astrocytes, ramified microglia, and brain macrophages to central neuronal infection with pseudorabies virus. J Neurosci 13:685-702.

Sesack SR, Pickel VM (1990) In the rat medial nucleus accumbens, hippocampal and catecholaminergic terminals converge on spiny neurons and are in apposition to each other. Brain Res 527:266-279.

Sesack SR, Deutch AY, Roth RH, Bunney BS (1989) Topographical organization of the efferent projections of the medial prefrontal cortex in the rat: an anterograde tract-tracing study with Phaseolus vulgaris leucoagglutinin. J Comp Neurol 290:213-242.

Siegel A, Fukushima T, Meibach R, Burke L, Edinger H, Weiner S (1977) The origin of the afferent supply to the mediodorsal thalamic nucleus: enhancement of HRP transport by selective lesions. Brain Res 135:11-23.

Snyder SH (1973) Amphetamine psychosis: a model of schizophrenia mediated by catecholamines. Am J Psychiatry 130:61-67.

Standish A, Enquist LW, Escardo JA, Schwaber JS (1995) Central neuronal circuit innervating the rat heart defined by transneuronal transport of pseudorabies virus. J Neurosci 15:1998-2012.

Steriade M, Llinás RR (1988) The functional states of the thalamus and the associated neuronal interplay. Physiol Rev 68:649-742.

Steriade M, Contreras D, Curró Dossi R, Nuñez A (1993a) The slow $(<1$ $\mathrm{Hz}$ ) oscillation in reticular thalamic and thalamocortical neurons: scenario of sleep rhythm generation in interacting thalamic and neocortical networks. J Neurosci 13:3284-3299.

Steriade M, McCormick DA, Sejnowski TJ (1993b) Thalamocortical oscillations in the sleeping and aroused brain. Science 262:679-685.
Steriade M, Contreras D, Amzica F (1994) Synchronized sleep oscillations and their paroxysmal developments. Trends Neurosci 17:199-208.

Strack AM, Loewy AD (1990) Pseudorabies virus: a highly specific transneuronal cell body marker in the sympathetic nervous system. J Neurosci 10:2139-2147.

Strack AM, Sawyer WB, Hughes JH, Platt KB, Loewy AD (1989) A general pattern of CNS innervation of the sympathetic outflow demonstrated by transneuronal pseudorabies viral infections. Brain Res 491:156-162.

Swanson LW, Cowan WM (1975) A note on the connections and development of the nucleus accumbens. Brain Res 92:324-330.

Tai Y, Yi H, Ilinsky IA, Kultas-Ilinsky K (1995) Nucleus reticularis thalami connections with the mediodorsal thalamic nucleus: a light and electron microscopic study in the monkey. Brain Res Bull 38:475-488.

Ugolini G (1995) Specificity of rabies virus as a transneuronal tracer of motor networks: transfer from hypoglossal motoneurons to connected second-order and higher order central nervous system cell groups. J Comp Neurol 356:457-480.

Vahlne A, Nystrom B, Sandberg M, Hamberger A, Lycke E (1978) Attachment of herpes simplex virus to neurons and glial cells. J Gen Virol 40:359.

Vahlne A, Svennerholm B, Sandberg M, Hamberger A, Lycke E (1980) Differences in attachment between herpes simplex type 1 and type 2 viruses to neurons and glial cells. Infect Immun 28:675.

Vizzard MA, Erickson VL, Card JP, Poppolo JR, de Groat WC (1995) Transneuronal labeling of neurons in the adult rat brain and spinal cord after injection of pseudorabies virus into the urethra. J Comp Neurol 355:629-640.

Watson RE, Wiegand ST, Clough RW, Hoffman GE (1986) Use of cryoprotectant to maintain long-term peptide immunoreactivity and tissue morphology. Peptides 7:155-159.

Woolf NJ, Butcher LL (1986) Cholinergic systems in the rat brain. III. Projections from the pontomesencephalic tegmentum to the thalamus, tectum, basal ganglia, and basal forebrain. Brain Res Bull 16:603-637.

Yang CR, Mogenson GJ (1984) Electrophysiological responses of neurones in the accumbens nucleus to hippocampal stimulation and the attenuation of the excitatory responses by the mesolimbic dopaminergic system. Brain Res 324:69-84.

Young WS, Alheid GF, Heimer L (1984) The ventral pallidal projection to the mediodorsal thalamus: a study with fluorescent retrograde tracers and immunohistofluorescence. J Neurosci 4:1626-1638.

Záborszky L, Cullinan WE (1992) Projections from the nucleus accumbens to cholinergic neurons of the ventral pallidum: a correlated light and electron microscopic double-immunolabeling study in rat. Brain Res 570:92-101.

Záborszky L, Alheid GF, Beinfeld ML, Eiden LF, Heimer L, Palkovits M (1985) Cholecystokinin innervation of the ventral striatum: a morphological and radioimmunological study. Neuroscience 14:427-453.

Zahm DS, Heimer L (1990) Two transpallidal pathways originating in the rat nucleus accumbens. J Comp Neurol 302:437-446.

Zahm DS, Heimer L (1993) Specificity in the efferent projections of the nucleus accumbens in the rat: comparison of the rostral pole projection patterns with those of the core and shell. J Comp Neurol 327:220-232.

Zahm DS, Williams E, Wohltmann C (1996) Ventral striatopallidothalamic projection. IV. Relative involvement of neurochemically distinct subterritories in the ventral pallidum and adjacent parts of the rostroventral forebrain. J Comp Neurol 364:340-362.

Zemanick MC, Strick PL, Dix RD (1991) Direction of transneuronal transport of herpes simplex virus 1 in the primate motor system is strain-dependent. Proc Natl Acad Sci USA 88:8048-8051. 